EFFECT OF ZINC OXIDE AND SILVER NANOPARTICLES ON INTESTINAL

BACTERIA

A Thesis presented to the Faculty of the Graduate School

University of Missouri

In Partial Fulfillment

of the Requirements for the Degree

Master of Science

by

AMI YOO

Dr. Azlin Mustapha, Thesis Supervisor

DECEMBER 2013 
The undersigned, appointed by the dean of the Graduate School, have examined the thesis entitled

\section{EFFECT OF ZINC OXIDE AND SILVER NANOPARTICLES ON INTESTINAL BACTERIA}

Presented by Ami Yoo, a candidate for the degree of Master of Science, and hereby certify that, in their opinion, it is worthy of acceptance.

Azlin Mustapha, Ph.D., Food Science Program

Mengshi Lin, Ph.D., Food Science Program

Zhiqiang Hu, Ph.D., Department of Civil and Environmental Engineering 
(C) Copyright by Ami Yoo 2013 All rights reserved. 


\section{ACKNOWLEDGEMENTS}

This thesis would not have been possible without the guidance and supports of each of following individuals.

I would like to first and foremost thank my advisor, Dr. Azlin Mustapha who was abundantly helpful and offered invaluable assistance, support and encouragement. Her enthusiastic guidance and warm encouragement helped me improve my knowledge and finish this thesis.

I would like to thank Dr. Mengshi Lin and Dr. Zhiqiang Hu for serving on my committee in spite of their busy schedules. I really appreciate their valuable suggestions and comments, without their assistance, this study would not have been successful.

I also would like to express my thanks to Dr. Ingolf U. Gruen, Dr. Andrew Clarke, and Dr. Bongkosh Vardhanabhuti for their enlightening classes; Ms. JoAnn Lewis for her assistance outside the class.

I would like to give a special appreciation to my colleagues in lab, Prashant Prashant, Yuan Yuan, Yarui Liu, Jisu Kang, Jee Hye Lee, Ruoyu Li, Tracy Bish. It was my pleasure to work with them. I also would like to thank Kathleen Kim for her encouragement outside of lab, Wen Wang Ritts and Juliana Pavlovna Arndt, the electron microscopy specialist at EMC for the training on the use of facilities and assistance.

Finally, I would like to express my sincere gratitude to my family for their endless love, encouragement, and support for me. 


\section{TABLE OF CONTENTS}

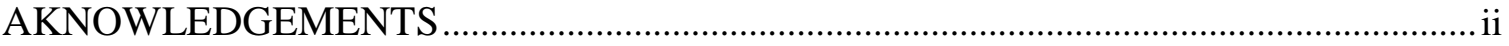

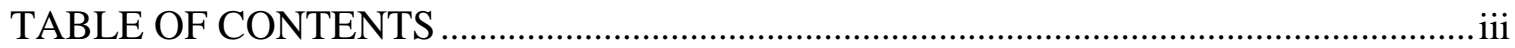

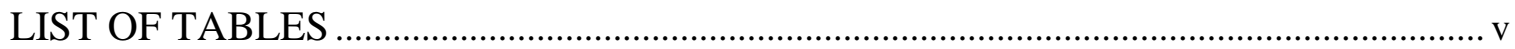

LIST OF FIGURES …............................................................................................ vi

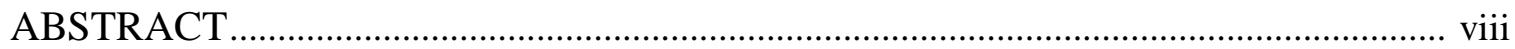

\section{Chapter}

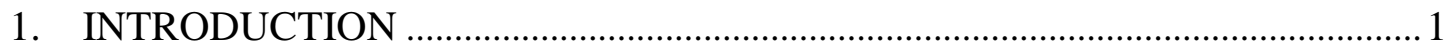

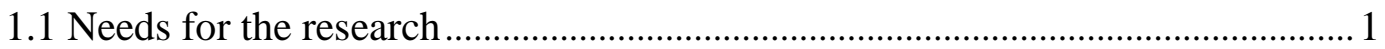

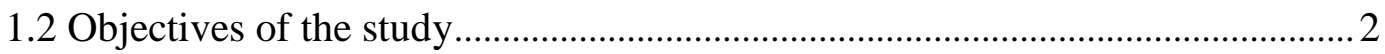

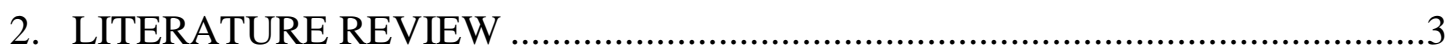

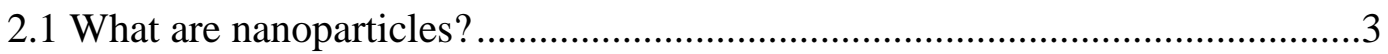

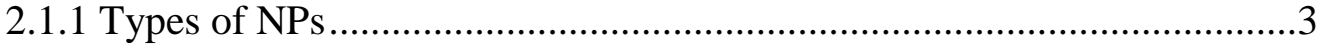

2.2 Applications of NPs in the food industry................................................

2.2.1 Antibacterial effect of metal-based NPs ............................................5

2.2.1.1 Mechanisms of NPs against bacteria ............................................6

2.2.1.2 Antibacterial effect of $\mathrm{ZnO}$ NPs ...................................................

2.2.1.3 Antibacterial effect of Ag NPs ...................................................10

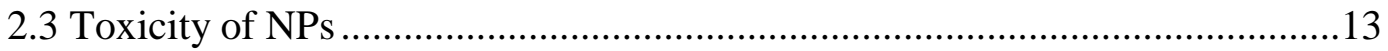

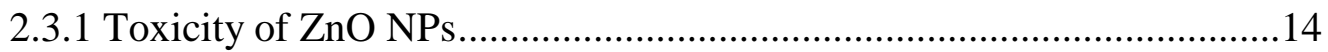

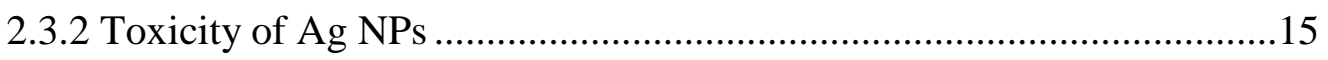

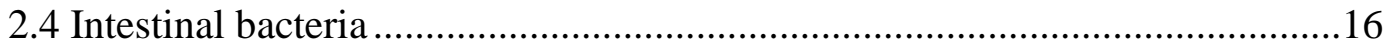

2.4.1 Functions of intestinal bacteria ...........................................................16

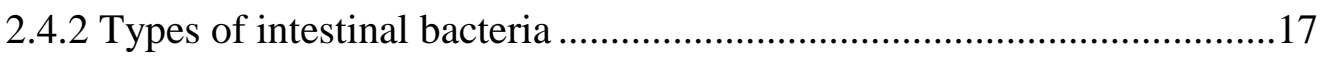




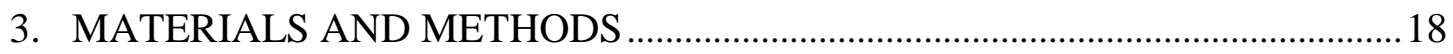

3.1 Preparation of intestinal bacterial strains ......................................................18

3.2 Perparation of zinc oxide and silver nanoparticles .........................................18

3.3 Effect of ZnO NPs on the growth of

E. coli K-12, L. acidophilus ADH, and B. animalis Bif-6.........................19

3.4 Effect of Ag NPs on the growth of

E. coli $\mathrm{K}-12$, L. acidophilus $\mathrm{ADH}$, and B. animalis Bif-6 ........................20

3.5 Morphological test of the bacterial cells ......................................................21

3.6 Determination of membrane leakage ...........................................................22

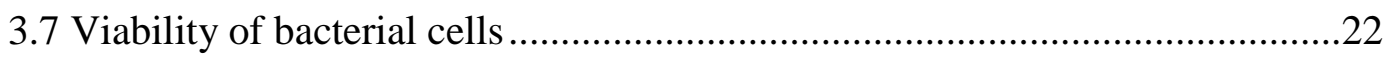

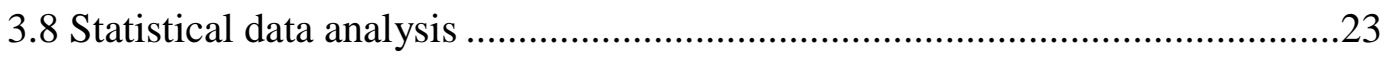

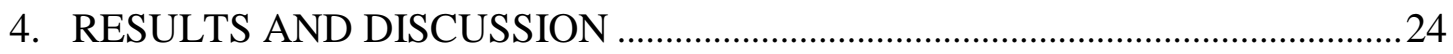

4.1 Effect of ZnO NPs on the growth of

E. coli K-12, L. acidophilus ADH, and B. animalis Bif-6........................24

4.2 Effect of Ag NPs on the growth of

E. coli K-12, L. acidophilus ADH, and B. animalis Bif-6........................29

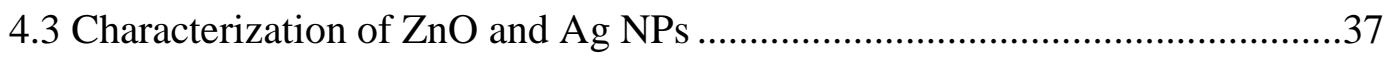

4.4 Morphological test of bacterial cells ............................................................42

4.4.1 Treated with ZnO NPs ....................................................................42

4.4.2 Treated with Ag NPs.........................................................................

4.5 Determination of membrane leakage ............................................................56

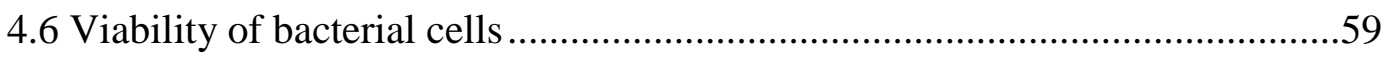

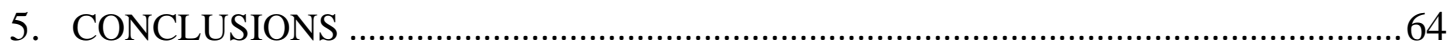

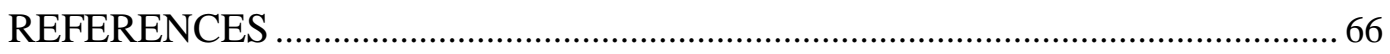




\section{LIST OF TABLES}

Figure $\quad$ Page

4.1 Number of L. acidophilus before and after treatment with

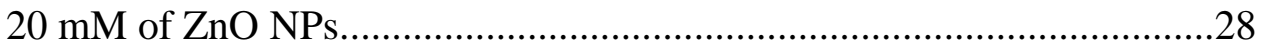

4.2 Number of B. animalis before and after treatment with

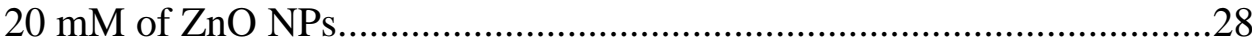

4.3 Number of E. coli before and after treatment with

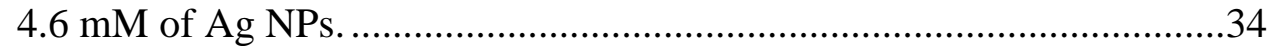

4.4 Number of L. acidophilus before and after treatment with

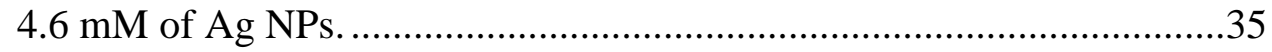

4.5 Number of B. aimalis before and after treatment with

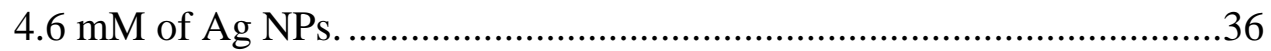




\section{LIST OF FIGURES}

Figure

Page

4.1 Effect of ZnO NPs on the growth of E. coli (A), L.acidophilus (B),

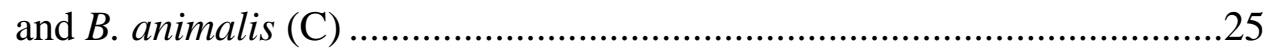

4.2 Effect of Ag NPs on the growth of E. coli (A), L.acidophilus (B),

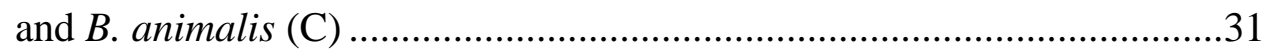

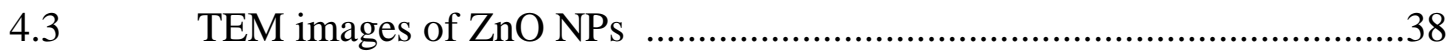

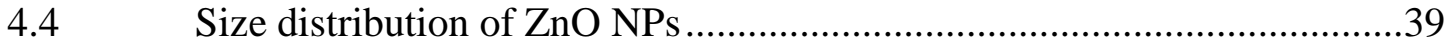

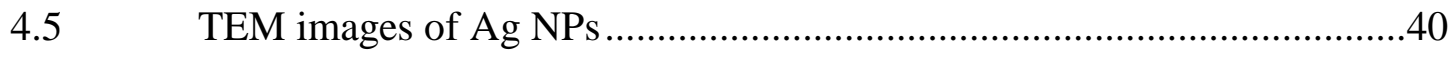

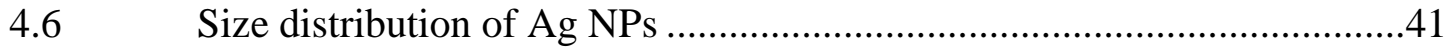

4.7 SEM images of E. coli with and without treatment of ZnO NPs..............43

4.8 TEM images of E. coli with and without treatment of ZnO NPs ............43

4.9 SEM images of L. acidophilus with and without treatment of ZnO NPs ..45

4.10 TEM images of L. acidophilus with and without treatment of ZnO NPs ..45

4.11 SEM images of $B$. animalis with and without treatment of $\mathrm{ZnO}$ NPs.......46

4.12 TEM images of B. animalis with and without treatment of $\mathrm{ZnO}$ NPs.......46

4.13 EDS spectroscopy of E. coli. B. animalis with and without

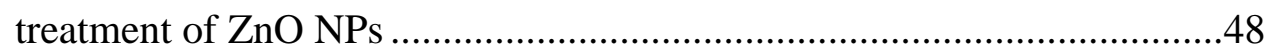

4.14 SEM images of E. coli with and without treatment of Ag NPs ................50

4.15 TEM images of E. coli with and without treatment of AgNPs .................50

4.16 SEM images of L.acidophilus with and without treatment of Ag NPs......52

4.17 TEM images of L.acidophilus with and without treatment of $\mathrm{ZnO}$ NPs ...52 
4.18 SEM images of B. animalis with and without treatment of $\mathrm{ZnO}$ NPs.......53

4.19 TEM images of B. animalis with and without treatment of $\mathrm{ZnO}$ NPs.......53

4.20 EDS spectroscopy of E. coli. B. animalis with and without treatement of

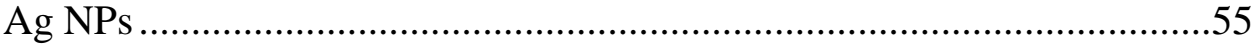

4.21 Absorbance of intracellular DNA leakage of E. coli (A), L.acidophilus (B), and B. animalis $(\mathrm{C})$ after treatment with $\mathrm{ZnO} \mathrm{NPs}$............................57

4.22 Absorbance of intracellular DNA leakage of E. coli (A), L.acidophilus (B), and $B$. animalis $(\mathrm{C})$ after treatment with $\mathrm{ZnO}$ NPs..............................58

4.23 Bac Light ${ }^{\mathrm{TM}}$ fluorescence microscopic images of cells untreated and treated with $\mathrm{ZnO}$ NPs..............................................................6. 62

4.24 BacLight ${ }^{\mathrm{TM}}$ fluorescence microscopic images of cells untreated and

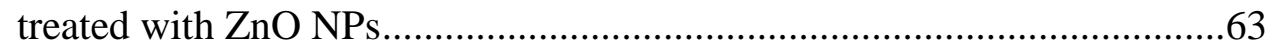




\title{
THE EFFECTS OF ZINC OXIDE AND SILVER NANOPARTICLES ON INTESTINAL BACTERIA
}

\author{
Ami Yoo \\ Dr. Azlin Mustapha, Thesis Supervisor
}

\begin{abstract}
In this study, the effects of zinc oxide $(\mathrm{ZnO})$ and silver $(\mathrm{Ag})$ nanoparticles (NPs) on the intestinal bacteria, Escherichia coli, Lactobacillus acidophilus, and Bifidobacterium animalis were investigated. All three bacterial strains were inoculated into tryptic soy broth (TSB) or Lactobacilli MRS broth media containing different concentrations of $\mathrm{ZnO}(0,12,16,20 \mathrm{mM})$ and $\mathrm{Ag}(0,1.8,2.7,4.6 \mathrm{mM}) \mathrm{NPs}$ and $1 \%$ of NP-free solution and incubated at $37{ }^{\circ} \mathrm{C}$ for $24 \mathrm{~h}$. The presence and characterization of $\mathrm{ZnO}$ and $\mathrm{Ag}$ NPs on bacterial cells were investigated by scanning electron microscopy (SEM), transmission electron microscopy (TEM), and energy-dispersive X-ray spectroscopy (EDS). UV-visible absorbance and the Live/Dead Bacterial Viability assay were performed to assess membrane leakage and viability of bacterial cells before and after treatment with the NPs.
\end{abstract}

For all bacteria, for up to $12 \mathrm{~h}$ of incubation, the numbers of treated cells were within 1 $\log \mathrm{CFU} / \mathrm{mL}$ less than that of the control. Morphological changes of bacterial cells were observed, but many cells remained in normal shapes. Results of UV-visible spectroscopy showed that only a small amount of internal cellular contents were leaked due to the NPs. 
Also, more live than dead cells were observed after exposure to the NPs. Results indicate that $\mathrm{ZnO}$ and $\mathrm{Ag}$ NPs have very mild inhibitory effects on intestinal bacteria. 


\section{CHAPTER 1}

\section{INTRODUCTIONS}

\subsection{Need for the research}

Nanotechnology is now applied in various industries, including electrical engineering, chemistry, material sciences and cosmetics (Kumar 2006). There is potential power of applications of nanotechnology in the many aspects of food industry such as food safety, disease treatment delivery methods, new tools for molecular and cellular biology, new materials for pathogen detection and protection of the environment (Weiss, Takhistov, and Clements 2006). NPs have been reported for their application in the nanosensor and nanotracer fields in the food industry (Moraru and others 2003; Jin and others 2009). Moreover, the application of nanotechnology to food packaging has been introduced to improve the shelf life of food and to prevent contamination (Duncan 2011; Maillard and Hartemann 2012). There are increasing numbers of foodborne outbreaks over the world, so it is important to control the causes of outbreak. NPs are one of the promising and useful antibacterial agents that could possibly be applied in the food industry. ZnO NPs are unique in that they are not only stable under high temperatures and pressures that are typically needed in food-processing conditions, but they are also generally regarded as safe (GRAS) for human beings and animals relative to organic materials (Sawai 2003; Fu and others 2005). Ag NPs are inorganic antibacterial agents used in the pharmaceutical and medical industries. Ag NPs have a significant potential for a wide range of 
biological applications, including as an antifungal and antibacterial agent for antibiotic resistant organisms and for preventing infections.

Recent studies (Sondi and Salopek-Sondi 2004; Brayer and others 2006; Kim and others 2007; Jones and others 2008; Martinez-Castanon 2008; Raffi and others 2009; Liu and others 2009; Jin and others 2009; Tayel 2010; Xie and others 2011; Mirhosseini and Firouzabadi 2013) have demonstrated the antimicrobial activities of $\mathrm{ZnO}$ and Ag NPs to pathogenic microorganisms, including Escherichia coli O157:H7, Staphylococcus aureus, Streptococcus pyogenes, Listeria monocytogenes, Salmonella Enteritidis, Salmonella Typhimurium Bacillus cereus, Campylobacter jejuni, Botrytis cinerea, and Penicillium expansum. However, not much is known about the behavior of $\mathrm{ZnO}$ and $\mathrm{Ag}$ NPs upon ingestion and whether they inhibit natural gut microflora.

\subsection{Objectives of the study}

In this study, we investigated the effect of $\mathrm{ZnO}$ and $\mathrm{Ag}$ NPs on three important intestinal bacteria, E. coli, L. acidophilus, and B. animalis. The modes of action of $\mathrm{ZnO}$ and $\mathrm{Ag}$ NPs on the growth of the bacterial cells were also studied by a combination of chemical analytical methods. 


\section{CHAPTER 2}

\section{LITERATURE REVIEW}

\subsection{What are nanoparticles?}

Nanotechnology is one of the great advancements in various industries that manipulate materials on the atomic or molecular scales. Resulting materials have new characteristics and functions with very small sizes; these smaller materials are referred to as nanomaterials or nanoparticles (NPs) and defined as particles that are less than $100 \mathrm{~nm}$ in at least one dimension (Meyer and Kuusi 2002). Nanomaterials have attracted great attention for their unique, superior, and dispensable properties that can be distinguished from conventional macroscopic materials. Their discrete property arises especially from their higher surface to volume ratios and increased percentage of atoms at the grain boundaries. They represent an important class of materials in the development of novel devices that will enable applications in many areas, such as the physical, biological, biomedical and pharmaceutical area (Sigel 1993; Suryanarayana 1995; Gleiter 2000; Lee, Yeo and Jeong 2003).

\subsubsection{Types of NPs}

There are many types of intentionally produced NPs, and a variety of others are expected to appear in the future. Most current NPs are classified into four types: Carbon-based materials, metal-based materials, dendrimers, and composites (USEPA 2007). The carbon-based materials are composed mostly of carbon, form of spheres, ellipsoid, or 
tubes. These types of nanomaterials can be applied to improved films and coatings, stronger and lighter materials. The metal based materials include quantum dots, gold, silver, and metal oxides NPs such as zinc oxide $(\mathrm{ZnO})$, titanium dioxide $\left(\mathrm{TiO}_{2}\right)$. The dendrimers are nanosized polymers built from branched units. The surface of dendrimers has numerous chain ends, which can be tailored to perform specific chemical functions which are useful properties for catalysis. Lastly, composites are nanomaterials that combine with two different NPs, or with larger, bulk-type materials. These materials are already applied in the auto parts and packaging industries to improve mechanical, thermal, and barrier properties. Currently, metal-based NPs, especially metal oxide NPs, are among the most highly produced NPs; their available applications include catalysis, sensors, environmental remediation, and personal care products (Kumar 2006). Because of their unique and novel properties, these various types of nanomaterials are highly desirable for applications in diverse area and their possible applications will continue to grow.

\subsection{Applications of NPs in the food industry}

Nanotechnology is now applied in various industries, including electrical engineering, chemistry, material sciences and cosmetics (Kumar 2006). Medicinal sciences are investigating the use of nanotechonology to improve medical diagnosis and treatments (Bennett and Schuubiers 2005; Howard and Kjems 2007; Andersen and others 2009). Also, there is potential power of application of nanotechnology in the many aspects of food industry such as food safety, disease treatment delivery methods, new tools for molecular and cellular biology, new materials for pathogen detection and protection of 
the environment (Weiss, Takhistov, and Clements 2006). NPs have been reported for their application in the nanosensor and nanotracer fields in the food industry (Moraru and others 2003; Jin and others 2009). Moreover, the application of nanotechnology to food packaging has been introduced to improve the shelf life of food and to prevent contamination (Duncan 2011; Maillard and Hartemann 2012). There are increasing numbers of foodborne outbreaks over the world so it is important to control the causes of

outbreak. NPs are one of the promising and useful antibacterial agents that could possibly be applied in the food industry.

\subsubsection{Antibacterial effect of metal-based NPs}

Antibacterial agents are of great importance to numerous industries, especially in the food industry. The antibacterial agents currently used in the food industry can be classified into two types: organic and inorganic agents (Zhang and others 2007). Inorganic antibacterial agents, such as NPs have received increasing attention in food applications because they are not only stable under high temperatures and pressures that are typically needed in food-processing conditions, but they are also generally regarded as safe (GRAS) for human beings and animals, relative to organic materials (Sawai 2003; Fu and others 2005). Recent studies show that some NPs have selective toxicity to bacteria but minimal effects on human cells (Reddy and others 2007). Because of these properties, NPs, especially metal-based NPs, have attracted much interest for the control of microorganisms, especially pathogens that cause infectious diseases. There are several factors that influence antibacterial effects of NPs on microorganisms. 


\subsubsection{Mechanisms of NPs against bacteria}

The exact mechanisms of antibacterial activity of NPs to different types of bacteria are not completely understood. However, several studies have suggested the following mechanisms of antibacterial effects of NPs.

First, NPs are able to attach to the cell membrane of bacteria by electrostatic interaction and break the integrity of the bacterial membrane (Thill and others 2006). The bacterial cell wall is designed to provide strength, rigidity, and shape, and to protect the cell from osmotic explosion and mechanical damage (Singleton 2004). The composition and structure of bacterial cell wall can be categorized into two types: Gram-positive (+) and Gram negative (-). Compared to Gram-positive cell wall, Gram-negative cell wall is more in complex both structurally and chemically. The structure of the cell wall plays an important role in influencing the effect of NPs to bacteria. According to a study by Ashkarran and others (2012), vancomycin (van)-functionalized $\mathrm{Ag} @ \mathrm{TiO}_{2} \mathrm{NPs}_{\text {save the }}$ capacity to target van-sensitive bacteria. The van-sensitive bacterium, Desulfotomaculum, was recognized by vancomycin, while the van-resistant bacteria were not recognized by vancomycin. This is because of the van-resistant bacteria cell wall, which has an additional outer membrane that covers the cell surface. There are some components found in Gram-negative bacteria, and not in Gram positives, which can oppose NPs to attachment onto cell walls; the possible mechanism is the extra layer of outer membranes and the pathogen-associated molecular patterns which include lipoplysaccharide, porins, and particular fragments of pepidoglycan. Bacterial cell wall properties can play a crucial role in diffusion of NPs inside biofilm matrixes (Baek and An, 2011). 
Second, the mechanisms of NPs against bacteria rely on composition, contact surface, essential properties of NPs and the species of bacteria. Many studies about the antibacterial effects of different types of NPs have reported. According to Baek and An (2011), copper oxide (CuO) NP is more inhibitory to E. coli, whereas $S$. aureus and Bacillus subtilis are less susceptible. The antibacterial effect of silver (Ag) NP is higher than $\mathrm{Cu}$ NP against E. coli and S. aureus (Lu, Brauer, and Botstein 2009). S. aureus and B. subtilis are more susceptible than E. coli to nickel oxide (NiO) and $\mathrm{ZnO}$ NPs. Among the NPs, including $\mathrm{CuO}, \mathrm{ZnO}, \mathrm{NiO}$, and antimony trioxide $\left(\mathrm{Sb}_{2} \mathrm{O}_{3}\right) \mathrm{NPs}$, tested against $E$. coli, S. aureus, and S. aureus, $\mathrm{CuO} \mathrm{NP}$ had most antibacterial effect, followed by $\mathrm{ZnO}$ (except for S. aureus), $\mathrm{NiO}$ and $\mathrm{Sb}_{2} \mathrm{O}_{3} \mathrm{NPs}$ (Baek and $\mathrm{An}, 2011$ ). The concentration of NPs appears to be related to their antibacterial effect. However, some of those studies disagree with one another, which indicate that the mechanisms of NP toxicity to bacteria are very complicated (Bolla and others 2011; Lara and others 2011; Musee and Thwala 2011). Thus, it is difficult to classify the NPs as beneficial NPs and/ or adverse NPs towards bacteria.

Another factor that can influence the growth of bacteria against NPs is the rate of bacterial growth. Bacteria that grow fast are more effectively inhibited by NPs than those that grow slow (Brown, Allison, and Gilbert 1998; Mah and O'Toole 2001). It is possible that the tolerance property of bacteria that grow slow is related to the expression of stress-response genes (Lu and others 2009; Stewart, 2002). Consequently, antibacterial effects highly depend on the particular strain. Another possibility might be the induction 
of intracellular reactive oxygen species, hydrogen peroxide which is a strong oxidizing agent that is harmful to bacterial cells (Jones and others, 2008; Sawai, 2003).

\subsubsection{Antibacterial effect of $\mathrm{ZnO} \mathrm{NPs}$}

Among the metal-based NPs, ZnO NPs is one of the most studied. In 2006, investigations into the antibacterial effect of $\mathrm{ZnO}$ NPs against $E$. coli, done by Brayner and others (2006), showed that as the concentration of ZnO NPs increased, the inhibition of bacterial growth also increased. The results showed that concentrations of $1.3 \mathrm{mM}$ or lower did not significantly affect the growth of E. coli. At concentrations of 3.0 to $10 \mathrm{mM}$, ZnO NPs showed 100-\% inhibition of bacterial growth.

Another study by Jones and other (2008) showed that ZnO NPs have inhibitory effect on various bacteria, including, S. aureus, S. epidermidis, S. pyogenes, and B. subtilis. Further studies by Jin and others (2009) showed that $\mathrm{ZnO}$ quantum dots and NPs of purified powdered $\mathrm{ZnO}$ were effective in decreasing numbers of Listeria monocytogenes, $S$. Enteritidis, and E. coli O157:H7. The reduction of cell number was greater at higher concentrations of $\mathrm{ZnO}$ NPs to all three strains. The result showed that $3.2 \mathrm{mg} \mathrm{ZnO} / \mathrm{mL}$ treatment caused a $5.3 \log$ reduction of L. monocytogenes and a $6.0 \log$ reduction of $E$. coli $\mathrm{O} 157: \mathrm{H} 7$ after a 2-day of incubation with ZnO NPs. The results of these studies demonstrated the antibacterial activity of $\mathrm{ZnO}$ NPs over a spectrum of bacteria. The growth reduction was greater at higher concentrations of $\mathrm{ZnO}$ NPs. According to a study by Liu and others (2009), where ZnO NPs concentrations of 3, 6, and $12 \mathrm{mM}$ were used to examine E. coli $\mathrm{O} 157: \mathrm{H} 7,3$ and $6 \mathrm{mM} \mathrm{ZnO}$ NPs resulted in less bacterial growth as 
compared to the control while the growth of E. coli O157:H7 was completely inhibited by $12 \mathrm{mM} \mathrm{ZnO}$ NPs.

Another study by Tayel (2010) showed that Gram-positive strains were more susceptible to $\mathrm{ZnO}$ NPs using both qualitative and quantitative assays. $\mathrm{ZnO} \mathrm{NP}$ was more effective to S.aures which is a Gram-positive bacterium than $S$. Typhimurium which is a Gramnegative bacterium. After exposure to their minimal inhibitory concentration of $\mathrm{ZnO} \mathrm{NP}$, $S$. Typhumurium and $S$. aureus cell numbers were reduced to 0 within 8 and $4 \mathrm{~h}$, respectively. Scanning electron micrographs of treated cell showed that the cells completely exploded or lysed. The results of this study also showed that Bacillus cereus was the most sensitive strains among all of the examined strains against $\mathrm{ZnO}$ NPs, and Psudomonas spp. were the most resistant.

Another study by Xie and others (2011) showed antibacterial activity of ZnO NPs against Campylobacter jejuni. The results showed that $C$. jejuni was extremely sensitive to $\mathrm{ZnO}$ NPs. The minimum inhibitory concentration (MIC) of ZnO NPs for C. jejuni was 0.05 to $0.025 \mathrm{mg} / \mathrm{mL}$, which is much lower than that of Salmonella enterica and E. coli O157:H7 $(0.4 \mathrm{mg} / \mathrm{mL})$. The action of $\mathrm{ZnO}$ NPs against $C$. jejuni was determined to be bactericidal, not bacteriostatic. The majority of $C$. jejuni cells, after exposure to ZnO NPs for $16 \mathrm{~h}$ had transformed from spiral shapes into coccoid forms.

A study by Mirhosseini and Firouzabadi (2013) demonstrated the antibacterial activity of ZnO NPs in food samples. Specifically, two concentrations, 5 and $10 \mathrm{mM}$, of ZnO NPs were used as antimicrobial treatments in milk samples inoculated with $E$. coli and $S$. 
aureus. As a result, after $8 \mathrm{~h}$ of incubation, the growth number of $S$. aureus treated with ZnO NPs in milk was $2 \log \mathrm{CFU} / \mathrm{mL}$ lower than its control, while the number of $E$. coli was less than $1 \log$ lower than the control. The antibacterial effect of $\mathrm{ZnO}$ NPs on $S$. aureus was stronger than $E$. coli in milk. These findings imply that antibacterial efficacy of $\mathrm{ZnO}$ NPs in food samples exists.

Also, different sizes of NPs influence their effectiveness against bacterial growth. The study done by Seil and Webster (2012), showed that the smaller size of ZnO NPs, the stronger the antibacterial effect. An increasingly positive surface charge (which results in the NPs being drawn to the negatively charged surface of the bacteria) is another characteristic that generally enhances the antibacterial effects of $\mathrm{ZnO}$ NPs.

More studies in recent years have been reported regarding the antimicrobial effects of $\mathrm{ZnO}$ NPs and their inhibitory mechanisms towards bacteria and fungi. Although there are no specific conclusions on the mechanisms of action $\mathrm{ZnO}$ NPs against bacteria, it is well recognized that the higher the concentrations, the greater the inhibitory effect.

\subsubsection{Antibacterial effect of Ag NPs}

Higher concentrations of Ag NPs have been shown to have the stronger antimicrobial effect. In 2004, a case study using Ag NPs as an antimicrobial agent on E. coli as the model for Gram negative bacteria was done by Sondi and Salopek-Sondi (2004). The results showed that a concentration of $10 \mu \mathrm{g} \mathrm{cm}^{-3} \mathrm{Ag}$ NPs inhibited bacterial growth by $70 \%$, and as the concentration got higher, the number of cells significantly reduced. The concentration of $50-60 \mu \mathrm{g} \mathrm{cm}^{-3}$ caused $100 \%$ inhibition of bacterial growth. Also, the 
dynamics of bacterial growth was observed in liquid medium with $10^{7} \mathrm{E}$. coli cells and 10, 50, and $100 \mu \mathrm{g} \mathrm{cm}^{-3} \mathrm{Ag}$ NPs. All of the three different concentrations caused a growth delay of E. coli and increasing the concentration of NPs increased the growth delay. According to a study by Kim and others (2007), yeasts and E. coli were inhibited at low concentrations of Ag NPs. However, S. aureus was less inhibited by Ag NPs compared to yeast and E. coli $\mathrm{O} 157: \mathrm{H7}$. To be more specific, the MIC of Ag NPs against yeast was between $6.6 \mathrm{nM}$ and $13.2 \mathrm{nM}$ and against $E$. coli $\mathrm{O} 157: \mathrm{H} 7$ was between $33 \mathrm{nM}$ and $6.6 \mathrm{nM}$. As the concentrations of Ag NPs got higher, the stronger inhibitory effects were observed. MIC of Ag NPs against S. aureus was estimated to be more than $33 \mathrm{nM}$. The growth-inhibitory effect was mild against $S$. aureus even in high concentrations of Ag NPs compared to other microorganisms used in this study. A study by Raffi and others (2009) also showed antibacterial effects against E. coli 15224 in both liquid and solid growth media. The number of CFU was significantly reduced with increasing concentrations of Ag NPs. The concentrations of Ag NPs, as low as $60 \mu \mathrm{g} / \mathrm{mL}$, showed complete cytoxicity to the $E$. coli bacterial strain.

A study by Martinez-Castanon (2008) showed that smaller sizes of Ag NPs have larger surface to volume ratio which makes interaction between bacterial cells and NPs and the resulting antibacterial effects stronger. Three different sizes (7, 29, and $89 \mathrm{~nm}$ mean value) were synthesized by an aqueous chemical reduction method and the standard microdilution method was used to determine antibacterial activity of Ag NPs. As a result, $7 \mathrm{~nm}$ Ag NPs was most effective against both E. coli and S. aureus. For E. coli, there was no significant difference between the MIC of 29 and $89 \mathrm{~nm} \mathrm{Ag} \mathrm{NPs.} \mathrm{Also,} \mathrm{the} \mathrm{MIC} \mathrm{of} \mathrm{all}$ 
samples was lower when testing against $E$. coli than when testing against $S$. aureus. This result is similar to that found by Kim and others (2007). These results can be explained on the basis of the differences in the cell wall composition of each strain explained as section 2.2.1.1 Mechanisms of NPs against bacteria.

Another study showed similar results between E. coli, S. aureus and Ag NPs (Liu 2010). However, Liu's study also shows that smaller Ag NPs had better antibacterial effects but higher cytotoxicity. In 2011, a study done by Guzman and others showed antibacterial activity of Ag NPs against not only E. coli and S. aureus, but also, Pseudomonas aeruginosa. The average particle sizes used were $9 \pm 2,14 \pm 5,24 \pm 6$, and $30 \pm 7 \mathrm{~nm}$ and the antibacterial activity was measured by the Kirby-Bauer method. As a result, the presence of NPs at a certain level inhibited bacterial growth by more than $90 \%$, and clearzone diameters increased as the concentration of Ag NPs increased in all three bacterial strains. To determine the MIC of Ag NPs against bacterial strains, a standard dilution micromethod was also performed. The smaller Ag NPs, $9 \pm 2$ and $14 \pm 5 \mathrm{~nm}$, showed considerable antibacterial activity. The MIC of Ag NPs on P. aeruginosa and E. coli were lower than that of $S$. aureus.

More studies have been reported concerning the antimicrobial effects of Ag NPs on a broad spectrum of microorganisms. It is well recognized that the higher the concentration and the smaller the particle size the greater the inhibitory effect on microorganisms. However, the mechanisms underlying inhibitory effects are not yet completely understood. 


\subsection{Toxicity of NPs}

Some believe that nanotechnology will make great developments and enhance the world and quality of life, while others regard nanotechnology as too dangerous and risky for continuing their research due to toxicity issues (Woodhouse 2004). This is because the interaction mechanisms between NPs and living cells are not yet fully understood. In recent years, many studies have been conducted on NP-cell interaction mechanisms. These studies found that cells readily take up NPs via either active or passive mechanisms. However, intracellular mechanisms and pathways are more difficult to understand due to the properties of NPs. Particles of the same material can show completely different characteristics with the slightest differences in surface coating, charge, or size (Li and others 2012). This makes it very difficult to define the behavior and hazard identification of NPs when in contact with biological systems.

Hazard identification of NPs at the in-vivo level is still considered at an early stage. The complexity increases when moving from an in vitro to in vivo model. The lung, gut, and possibly skin are the major entry routes that have been identified ( $\mathrm{Li}$ and others 2012). However, much more research are needed to better understand mechanisms and pathways of NPs in the body following their ingestion or exposure. Some NPs seem to be able to take a pre-existing transport mechanism through the body using endocytotic mechanisms which is the same method that viruses do (Elsaesser and Howard 2012). Therefore, if the body is exposed to NPs, people have to be aware of the risk of toxicity of NPs. 


\subsubsection{Toxicity of ZnO NPs}

$\mathrm{ZnO}$ NP powders are widely used in cosmetics, pigments, coating electronic devices, and catalysts. Despite the widespread use of ZnO NPs, the safety of this compound for humans is still not clear. Studies about the toxicity of ZnO NPs and other metal oxide NPs to mammalian cell and organs have been reported (Wang and others 2008, 2010; Liu and others 2009) ZnO NPs were found to cause more severe damage than other metal oxide NPs in many cases (Lai and others 2008). Skin exposures via products and manufacturers inhalation during processing are predominant exposure ways of $\mathrm{ZnO}$ NPs. A study by Jeng and Swanson (2006) showed that mice exposed to ZnO NPs at 100 $\mathrm{g} / \mathrm{mL}$ or higher concentration became abnormal in size, and resulted in cellular shrinkage. Concentrations of $\mathrm{ZnO}$ less than $100 \mathrm{~g} / \mathrm{ml}$ caused a substantial decrease of mitochondrial function. Also, lactate dehydrogenase leakage and apoptosis were observed in cells that were exposed to $\mathrm{ZnO}$ NPs. According to another study done by Wang and others in 2008 through 2010, inhalation of $20 \mathrm{~nm} \mathrm{ZnO} \mathrm{NPs} \mathrm{(2.5} \mathrm{mg/kg} \mathrm{bw)} \mathrm{by}$ rats twice a day for 2 days resulted in an increased $\mathrm{Zn}$ content in liver after $12 \mathrm{~h}$ and in the kidney after $36 \mathrm{~h}$. Histopathology revealed damage in liver and lung tissues. Also, 20 and $120 \mathrm{~nm} \mathrm{ZnO}$ NPs were discovered in the bone, kidney, and pancreas in healthy adult mice after exposed to ZnO NPs. Lin and others (2009) found both micro- and nano-sized $\mathrm{ZnO}$ particles in human lung epithelial cells, which indicated that showed exposure to both size of $\mathrm{ZnO}$ particles could lead to cytotoxicity.

The potential risk of $\mathrm{ZnO}$ NPs to human health and environment is an inevitable thing, although scientists continue to look for the mechanisms underlying the toxic effects. 
People who are vulnerable to $\mathrm{ZnO}$ NPs such as manufacturers, always have to be aware of the risk and handle the materials with extreme caution.

\subsubsection{Toxicity of Ag NPs}

Ag NPs is now able to access human daily life via a variety of commercial products. The use of Ag NPs in cosmetics and textiles has considerably increased the potential for human skin exposure. According to previous studies, Ag NPs were found to be toxic to keratinocytes and fibroblasts and induced cell death and oxidative stress in human fibrosarcoma and skin carcinoma cells (Lam and others 2004; Poon and Burd 2004; Paddle-Ledinek, Nasa, and Cleland 2006; Arora and others 2008; Arora and others 2009). During its manufacturing, manufacturers are exposed to Ag NPs via inhalation of airborne particles. Currently, the American Conference of Governmental Industrial Hygienist (ACGIH) limits the level of Ag dust in the air at a dose of $100 \mathrm{~g} / \mathrm{m}^{3}$. Inhalation exposure studies showed that the lung is an the easy target for NPs and that inhaled particles may reach the brain through the nasopharyngeal system (Oberdorster and others 2004). Soto and others (2007) reported that Ag NPs reduced the cell viability of lung epithelial cells. There is a series of inhalation studies focusing on the acute, subacute (28 days) and subchronic (90 days) toxicity of Ag NP in rats (Ji and others 2007; Sung and others. 2009, 2010). Results showed that a high-dose chronic exposure to Ag NP has the potential to cause harm under current guidelines and limits.

Ag NPs have emerged as important nanomaterials for a wide range of industrial and medical applications that have potential risks to human health. To apply not only Ag NPs, 
but other NPs safely in various fields, a detailed understanding of the biocompatibility and toxicity of NPs are needed.

\subsection{Intestinal bacteria}

The human gut is the natural habitat for a large and dynamic bacterial community. Many species of bacteria have evolved and are adapted to live and grow in the human intestine. An individual's intestine contains 300-500 different species of bacteria (Simon and Gorbach 1984; Borriello 1986). The stomach and small intestine contain only a few species of bacteria adhering to the epithelia and some other bacteria in transit. In contrast, the large intestine contains a complex and dynamic microbial ecosystem with high densities of living bacteria, with concentrations of up to $10^{11}$ or $10^{12}$ cells/g. These concentrations are similar to those found in colonies growing under optimum conditions over the surface of a laboratory plate (Levison 1990). The constant interaction between the host and its microbial system can infer important health benefits to the human host (Salminen and others, 1998).

\subsubsection{Functions of intestinal bacteria}

Major functions of the gut microflora include metabolic activities, trophic effects, and protective functions (Guarner and Malagelada, 2003).

Metabolic activities: A major metabolic function of colonic microflora is fermentation of non-digestible dietary residue and endogenous mucus produce by the epithelia (Roberfroid and others 1995). Various kinds of microbes provide different kinds of enzymes and biochemical pathways that are distinct from the host's own constitutive 
resources. Another role of colonic microbes is synthesizing vitamins and helping in the absorption of calcium, magnesium, and iron (Roberfroid and others 1995; Miyazawa and others 1996; Younes and others 2001)

Trophic activities: An important trophic effect is controlling epithelial cell proliferation and differentiation. All three major short-chain fatty acids stimulate epithelial cell proliferation and differentiation in the large and small intestine (Franke and others 1994). Interactions between gut bacteria and host immunity are another trophic activity. The intestinal mucosa is the man interface between the immune system and the external environment. The interaction between host and bacteria at the mucosal interface plays an important role in development of a competent immune system (Guarner and Malagelada 2003).

Protective activities: Intestinal bacteria are important in that they prevent species that are harmful to the host from colonizing the host and they protect against invasion by external microbes which is called barrier effect (Guarner and Malagelada 2003).

\subsubsection{Types of intestinal bacteria}

Not all microbial species in the gut have been identified because of the difficulty of identification. The genera of intestinal bacteria include, Bifidobacterium, Clostridium, Eubacterium, Peptococcus, Peptostreptococcus, and Ruminococcus, which are the predominant ones in humans. Also, there are sub-dominant genera, such as Escherichia, Enterobacter, Enterococcus, Klebsiella, Lactobacillus, Proteus, and others. (Simon and Gorbach 1984; Salminen and others 1998). 


\section{CHAPTER 3}

\section{MATERIALS AND METHODS}

\subsection{Preparation of intestinal bacterial strains}

Escherichia coli K-12, Lactobacillus acidophilus ADH, and Bifidobacterium animalis Bif-6 were provided by the Food Microbiology Laboratory at University of Missouri, Columbia, MO. E. coli K-12 was grown in tryptic soy broth supplemented with $0.5 \%$ yeast extract (TSBY; Difco Labs., BD Dignostics Systems, Sparks, MD, USA). L. acidophilus $\mathrm{ADH}$ and B. animalis Bif-6 were grown in Lactobacilli MRS broth (Difco Labs.) supplemented with $0.05 \%$ cysteine. All three strains were freshly prepared by transferring $100 \mu \mathrm{L}$ of each culture into separate tubes of $10 \mathrm{~mL}$ respective broth media. Tubes were incubated -aerobiacally for E. coli and anaerobically for the other two strains for 18 to $20 \mathrm{~h}$ at $37^{\circ} \mathrm{C}\left(\sim 10^{9} \mathrm{CFU} / \mathrm{mL}\right)$.

\subsection{Preparation of zinc oxide and silver nanoparticles}

$\mathrm{ZnO}$ NP suspensions with an average particle sized of $77 \mathrm{~nm}$ were purchased from Alfa Aesar (Ward Hill, MA, USA). The concentration of the original suspensions was $12 \mathrm{M}$.

Ag NPs were synthesized by using a chemical reduction method (Ratyakshi and Chauhan 2009). Silver nitrite $\left(\mathrm{AgNO}_{3}\right)$ and sodium citrate $\left(\mathrm{C}_{6} \mathrm{H}_{5} \mathrm{O}_{7} \mathrm{Na}_{3}\right)$ were prepared in deionized water. Then, $300 \mathrm{~mL}$ of $1 \mathrm{mM} \mathrm{AgNO} 3$ and $300 \mathrm{~mL}$ of $20 \mathrm{mM}$ of sodium citrate were separately heated to boiling. When both solutions reached $100{ }^{\circ} \mathrm{C}$, sodium citrate was added slowly to $\mathrm{AgNO}_{3}$. The mixture was boiled with continuous stirring. The 
solution was heated for 8 min until it turned a pale yellow color. The solution was cooled to room temperature and centrifuged at 3,290 $\times \mathrm{g}$ for $20 \mathrm{~min}$. Then, $90 \%$ of the supernatant was removed from the centrifuged solution. The final concentration of $\mathrm{Ag}$ NP solution was $9.2 \mathrm{mM}$. The size of $\mathrm{ZnO}$ NPs and Ag NPs were determined by analyzing transmission electron microscopy (TEM) images using ImageJ software available at http://rsb.info.nih.gov/ij/.

\subsection{Effect of ZnO NPs on the growth of E. coli K-12, L. acidophilus ADH, and B. animalis Bif-6}

All three strains, incubated overnight in respective broth media, TSBY and MRS 0, were inoculated into broth media containing different concentrations $(0,12,16,20 \mathrm{mM})$ of ZnO NP suspensions, and 1\% of NP-free solution. The NP-free solution was prepared by filtering $\mathrm{ZnO} \mathrm{NP}$ suspensions through an anodisc inorganic membrane with a $20 \mathrm{~nm}$ pore size (Whatman Inc., Clifton, NJ, USA). Both ZnO NP suspensions and the NP-free solution were added to the broth media before autoclaving.

After inoculating the cultures to the broth media, TSB or MRS, containing ZnO NP suspensions and NP-free solution, were incubated at $37{ }^{\circ} \mathrm{C}$ in a shaking incubator. The tubes inoculated with L. acidophilus ADH and B. animalis Bif-6 were placed in an anaerobic jar with GasPak (BD, GasPak EZ Anaerobe Container System) and incubated in a shaking incubator (Lab-Line 3528 Shaking incubator). The reason for using a shaking incubator was to avoid the aggregation of $\mathrm{ZnO}$ NPs in the broth and to allow a consistent contact between the bacterial cells and $\mathrm{ZnO}$ NPs. The samples were diluted 
with peptone water and plated on respective agar media, Tryptic Soy Agar supplemented with yeast extract for E. coli K-12 and Lactobacilli MRS agar supplemented with cysteine for $L$. acidophilus $\mathrm{ADH}$ and B. animails Bif-6, at $0,6,7,8,9,10,11,12,15$, and $24 \mathrm{~h}$.

\subsection{Effect of Ag NPs on the growth of E. coli K-12, L. acidophilus ADH, and B. animalis Bif-6}

All three strains, incubated overnight in respective broth media, TSBY and MRS, were inoculated into broth media containing different concentrations of Ag NP solution $(0,1.8$, 2.7, $4.6 \mathrm{mM}$ ), and $1 \%$ of NP-free solution. For concentrations of $\mathrm{Ag} \mathrm{NPs}, \mathrm{mg} / \mathrm{mL}$ unit was converted into $\mathrm{mM}$ unit. The NP-free solution was prepared by filtering the Ag NP solutions using an anodisc inorganic membrane (Whatman Inc.) with a pore size of 20 $\mathrm{nm}$. Both Ag NP suspensions and the NP-free solution were added to the broth media before autoclaving.

After inoculating the cultures into the TSB or MRS broth media containing Ag NP suspensions and NP-free solution, samples were incubated at $37{ }^{\circ} \mathrm{C}$ in a shaking incubator. The tubes inoculated with $L$. acidophilus ADH and B. animalis Bif-6 were placed in an anaerobic jar with GasPak (BD) and incubated in a shaking incubator. The samples were diluted with peptone water and plated on respective agar media, Tryptic Soy Agar supplemented with yeast extract for E. coli K-12 and Lactobacilli MRS agar supplemented with cysteine for L. acidophilus $\mathrm{ADH}$ and B. animails Bif-6, at 0, 1, 2, 3, 4, $5,6,9,12$, and $24 \mathrm{~h}$. 


\subsection{Morphological test of the bacterial cells}

Scanning electron microscopy (SEM) was used to examine morphological changes of the bacterial cells before and after treating with ZnO NPs and Ag NPs. The three bacterial strains treated or untreated with NPs were fixed with a primary fixative (2.5 glutaraldehyde, $2 \%$ paraformaldehyde in $0.1 \mathrm{M} \mathrm{Na-Cacodylate} \mathrm{buffer,} \mathrm{pH}$ 7.4). The samples were then rinsed three times with ultrapure water, followed by dehydration with a series of ethanol solutions $(10,30,50,70,90$, and $100 \%)$. The dehydrated samples were immediately dried by a critical point dryer (Auto-Samdri 815 Automatic Critical Point Dryer; Tousimis, Rockville, MD, USA), mounted on SEM stubs and coated with a thin layer of carbon using a sputter coater (K575X Turbo Sputter Coater; Emitech, Ltd, Kent, UK). The coated samples were observed under SEM (FEI Quanta 600, FEI Company, Hillsboro, OR, USA).

Transmission electron microscopy (TEM) was used to characterize the size of the NPs and to observe the morphology of bacterial cells after treatment with ZnO NPs and Ag NPs. Three samples of bacterial cells treated with and without NPs were fixed with a primary fixative and microwaved under vacuum conditions in a Pelco Biowave (Ted Pella, Inc., Redding, CA, USA) at $120 \mathrm{~W}$. The samples were rinsed with $0.1 \mathrm{M}$ cacodylate buffer and embedded in histogel, followed by a secondary microwave fixation with a buffered ( $0.1 \mathrm{M}$ cacodylate, $0.01 \mathrm{M}$ of 2-mercaptoethanol, and $0.13 \mathrm{M}$ of sucrose) $1 \%$ osmium tetroxide. The samples were then quickly rinsed three times with $0.1 \mathrm{M} 2$ mercaptoethanol, $0.13 \mathrm{M}$ of sucrose and then rinsed three times with ultrapure water. Then, samples were dehydrated with ethanol solutions (20, 50, 70, 90, and 100\%) and 
$100 \%$ acetone solution. The samples were infiltrated with Spurr's resin and polymerized at $60{ }^{\circ} \mathrm{C}$ for $24 \mathrm{~h}$. The sample blocks were processed in $85 \mathrm{~nm}$ thin sections with Leica Ultracut UCT ultramicrotomes (Leica Microsystems GmbH, Wetzlar, Germany). The sections were placed onto 200 mesh thin bar grids and post-stained for 20 min with 5\% uranyl acetate and 10 min with Sato's triple lead stain. Stained samples were then observed in JEOL 1400 (JEOL, Ltd, Tokyo, Japan).

\subsection{Determination of membrane leakage}

Overnight cultures of the three strains were inoculated into the respective broth medium containing different concentrations of $\mathrm{ZnO}$ NPs $(0,12,16,20 \mathrm{mM})$ and allowed to sit for $10 \mathrm{~h}$ at $37^{\circ} \mathrm{C}$. Similarly, strains were exposed to Ag NPs $(0,1.8,2.7,4.6 \mathrm{mM})$ for $6 \mathrm{~h}$ at $37{ }^{\circ} \mathrm{C}$. After incubation, $1 \mathrm{~mL}$ of the treated bacterial suspension was centrifuged at $18,200 \times g$ for $5 \mathrm{~min}$ and resuspended in peptone water. The light absorbance of the suspensions was examined using a UV-visible spectrophotometer (UV-1650 PC, Suzhou Instruments Manufacturing Co. Ltd, Suzhou, China) at a wavelength of $260 \mathrm{~nm}$ (for DNA absorbance) and $280 \mathrm{~nm}$ (for protein absorbance). All experiments were replicated twice.

\subsection{Viability of bacterial cells}

To determine the viability of the treated cells, $1 \mathrm{~mL}$ of the samples was centrifuged at $18,200 \times g$ for $5 \mathrm{~min}$. Cell pellets were washed with $1 \mathrm{~mL}$ of $0.85 \% \mathrm{NaCl}$ and stained using the BacLight ${ }^{\mathrm{TM}}$ Bacterial Viability Kit (Invitrogen, Carlsbad, CA, USA) according to the manufacturer's instructions. Equal volumes of Component A (SYTO 9 dye) and component B (propidium iodide) were mixed thoroughly and $3 \mu \mathrm{L}$ of the dye mixture 
was added to each $\mathrm{mL}$ of the bacterial suspension. The samples were incubated at room temperature in the dark for 15 min and $8 \mu \mathrm{L}$ of the stained bacterial suspension were placed between a glass slide and $170 \mu \mathrm{m}$ thick coverslip. Then samples were observed under a Zeiss LSM 510 META (Zeiss LSM 510 META NLO, Carl Zeiss Ltd, Jena, Germany).

\subsection{Statistical data analysis}

The SAS GLM procedure (SAS 9.2, Copyright 2002-2007; SAS Institute Inc., Cary, NC, USA) was used to evaluate the effects of $\mathrm{ZnO}$ and Ag NPs on growth of bacterial strains. Tukey's test was applied to determine differences between different concentrations of NPs with a significance level of 0.05 . 


\section{CHAPTER 4}

\section{RESULTS AND DISCUSSION}

\subsection{Effect of ZnO NPs on the growth of E. coli K-12, L. acidophilus ADH, and B. animalis Bif-6}

The same concentrations $(3,6,12 \mathrm{mM})$ of NPs were used to assess the effect of ZnO NPs on E. coli, L. acidophilus, and B. animalis. Increasing antimicrobial effects against E. coli O157:H7 were found as the concentration of ZnO NPs increased, and a treatment of 12 $\mathrm{mM}$ showed complete inhibition of the organism. No significant differences $(P \leq .05)$ between the control and treatments of 3 and $6 \mathrm{mM} \mathrm{ZnO} \mathrm{NPs} \mathrm{on} \mathrm{all} \mathrm{three} \mathrm{bacteria} \mathrm{were}$ found (data not shown). Hence, the higher concentrations (12, 16, $20 \mathrm{mM})$ of $\mathrm{ZnO}$ NPs were used for further experiments. Figure 4.1 shows the growth curves of E. coli, $L$. acidophilus, and B. animalis with different concentrations of ZnO NPs and NP-free solution. As shown in Figure 4.1A, the E. coli growth curve of the control and all treated samples including the NP-free sample, exhibited very similar patterns. Even at the highest concentration of ZnO NPs $(20 \mathrm{mM})$, no significant effects on $E$. coli $(P \leq .05)$ were observed. For L. acidophilus, for up to $12 \mathrm{~h}$ of incubation, the numbers of treated cells were within $1 \log \mathrm{CFU} / \mathrm{mL}$ less that of the control. All three treatments of $\mathrm{ZnO}$ NPs showed similar growth patterns. After $12 \mathrm{~h}$, the cell numbers of treated samples picked up slowly and by the end of $24 \mathrm{~h}$, their numbers showed no differences as compared $(P$ $\leq .05$ ) to the control. This result can be explained by previous study (Martinez-Castanon 2008) that showed that not only particle size and concentration of NPs, but also time can 

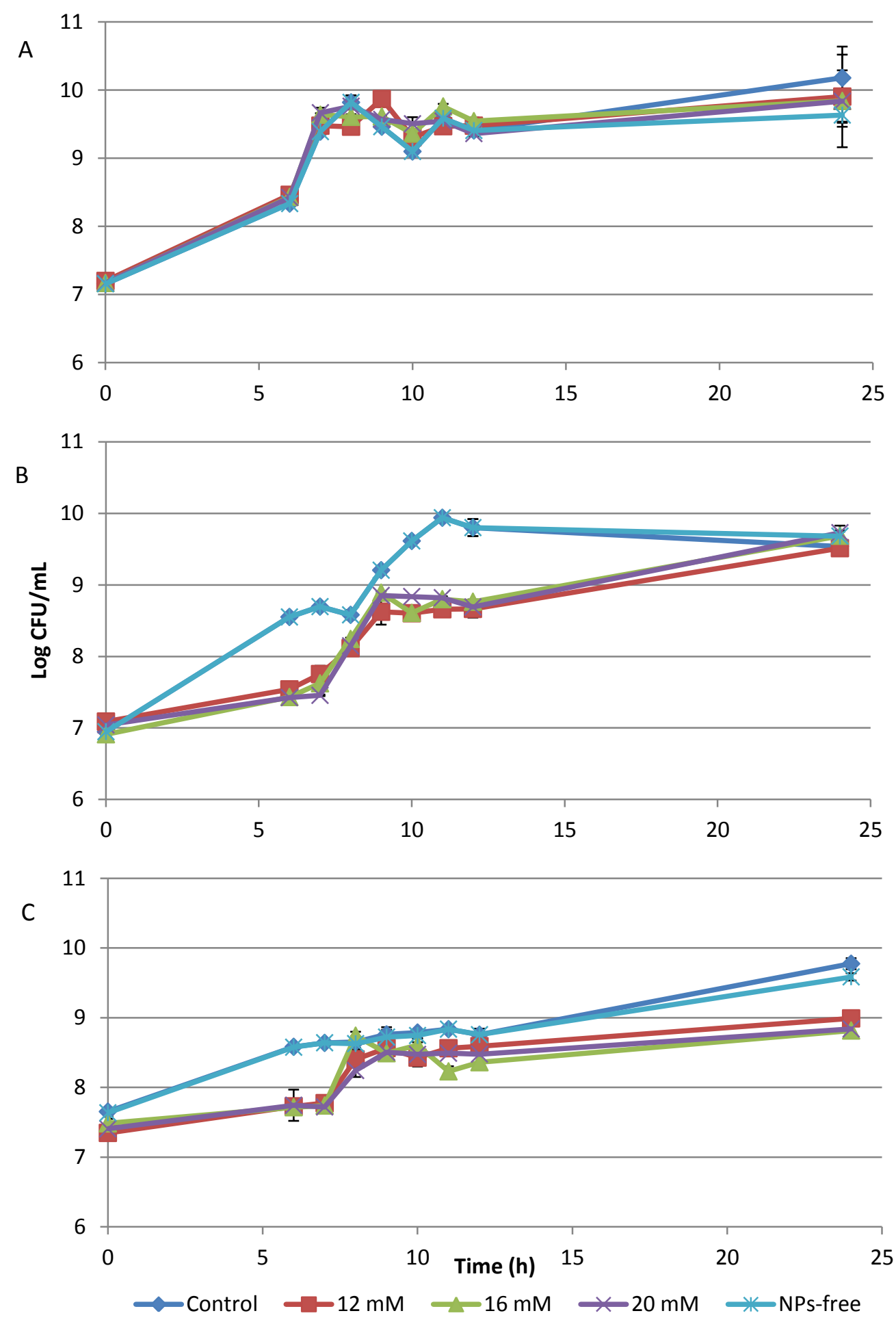

Figure 4.1 Effects of ZnO NPs on the growth of E. coli (A), L. acidophilus (B) and B. animals (C). 
affect the antibacterial activity of NPs. For $B$. animalis, until $7 \mathrm{~h}$ of incubation, cell numbers of treated samples were less than $1 \log \mathrm{CFU} / \mathrm{mL}$ as compared to the control. After $8 \mathrm{~h}$, the number of treated cells followed similar patterns of the control and NP-free sample. By the end of $24 \mathrm{~h}$, the numbers of treated cells were within $1 \log \mathrm{CFU} / \mathrm{mL}$ that of the control. As shown in Table 4.1, L. acidophilus after $10 \mathrm{~h}$ of exposure to ZnO NPs showed $11.4 \%$ reduction in the number of cells which was the highest percentage compared to the other exposure times. For B. animalis, between 6 and $7 \mathrm{~h}$ of exposure to $\mathrm{ZnO}$ NPs about $10 \%$ of reduction was observed. After that, less than $5 \%$ of reductions were observed. However, at the end of $24 \mathrm{~h}$ of exposure, more than $10 \%$ reduction in the number of cells was observed.

The results (Figure 4.1) indicated that concentrations of ZnO NPs higher than $12 \mathrm{mM}$ showed mild inhibition effects on growth of L. acidophilus and B. animalis, which are gram-positive bacteria, and no inhibition effects on growth of E. coli, which is a gramnegative bacterium. Similar results were observed in recent a study by Baek and An (2011). S. aureus and B. subtilis (gram-positive) were more susceptible than E. coli (gram-negative) to nickel oxide (NiO) and $\mathrm{ZnO}$ NPs. It is currently impossible to explain the species sensitivity in terms of bacterial classification (Gram + and - ). The biosorption of metal NPs to bacterial cells depends on not only the types of NPs, but also the microbial species (Hassen and others 1998). One possible mechanism of antimicrobial effects of ZnO NPs is suggested in several studies (Sawai 2003; Ghule and others 2006; Jones and others 2008; Li and others 2008). Antimicrobial effects of NPs are generally triggered by the induction of oxidative stress by free radical formation, ROS, and result in 
cell death. According to Pan and others (2010), ZnO NPs have weak mutagenic properties that induce frameshift mutations in $S$. Typhimurium. The presence of the $S 9$ fraction is necessary to cause frameshift mutations using $\mathrm{ZnO}$ NPs. S9 fraction is the product of an organ tissue homogenate that used to assess the mutagenic potential of chemical compound (Sakura and others 2004). It is possible that the S9 fraction increased the internalization of NPs and increases the generation of reactive oxygen species (ROS) that induce frameshift mutations in the bacteria. However, there are many reports about the antibacterial effect of NPs that contradict one another which indicate that the mechanisms of antimicrobial are very complicated and depend on many other factors. Also, there are several bacteria that naturally adapt to toxins or NPs that are present in the environment and become tolerant to the compounds ( $\mathrm{Wu}$ and others 2010). There is a possibility that this might be the reason for our observations of no inhibitory effects of ZnO NPs on E. coli in this study. 
Table 4.1 Number of L. acidophilus before and after treatment with $20 \mathrm{mM}$ of ZnO NPs.

\begin{tabular}{cccc}
\hline \multirow{2}{*}{$\begin{array}{c}\text { Time of incubation } \\
\text { (h) }\end{array}$} & \multicolumn{2}{c}{ Number of colonies $(\mathrm{CFU} / \mathrm{mL})$} & \\
\cline { 2 - 3 } & $8.9 \times 10^{6}$ & Treatment with ZnO & \% of Reduction \\
\hline 0 & $3.0 \times 10^{8}{ }_{\mathrm{a}}$ & $3.4 \times 10^{7} \mathrm{~b}$ & -1.3 \\
6 & $4.1 \times 10^{8}{ }_{\mathrm{a}}$ & $4.5 \times 10^{7} \mathrm{~b}$ & 11.1 \\
7 & $4.3 \times 10^{8}$ & $1.4 \times 10^{8}$ & 11.1 \\
8 & $1.6 \times 10^{9}$ & $7.1 \times 10^{8}$ & 5.5 \\
9 & $4.1 \times 10^{9}{ }_{\mathrm{a}}^{7}$ & $3.3 \times 10^{8} \mathrm{~b}$ & 3.8 \\
10 & $8.7 \times 10^{9}{ }_{\mathrm{a}}$ & $6.6 \times 10^{8}{ }_{\mathrm{b}}$ & 11.4 \\
11 & $6.3 \times 10^{9}{ }_{\mathrm{a}}$ & $4.9 \times 10^{8}{ }_{\mathrm{b}}$ & 11.2 \\
12 & $3.5 \times 10^{9}$ & $5.4 \times 10^{9}$ & 11.3 \\
24 & & & -1.99 \\
\hline
\end{tabular}

ab Different letters between columns indicate significant differences at a level of 0.05 .

Table 4.2 Number of B. animalis before and after treatment with $20 \mathrm{mM}$ of ZnO NPs.

\begin{tabular}{cccc}
\hline \multirow{2}{*}{$\begin{array}{c}\text { Time of incubation } \\
\text { (h) }\end{array}$} & \multicolumn{2}{c}{ Number of colonies (CFU/mL) } & \\
\cline { 2 - 3 } & Control & Treatment with ZnO & \% of Reduction \\
\hline 0 & $4.5 \times 10^{7}$ & $2.1 \times 10^{7}$ & \\
\hline 6 & $3.8 \times 10^{8}{ }_{\mathrm{a}}$ & $9.2 \times 10^{7} \mathrm{~b}$ & 3.2 \\
7 & $4.4 \times 10^{8} \mathrm{a}$ & $8.2 \times 10^{7} \mathrm{~b}$ & 9.7 \\
8 & $4.5 \times 10^{8}$ & $1.9 \times 10^{8}$ & 10.6 \\
9 & $5.8 \times 10^{8}$ & $2.1 \times 10^{8}$ & 4.7 \\
10 & $6.1 \times 10^{8}$ & $1.8 \times 10^{8}$ & 2.9 \\
11 & $6.9 \times 10^{8}$ & $2.8 \times 10^{8}$ & 3.5 \\
12 & $5.7 \times 10^{8}$ & $3.0 \times 10^{8}$ & 3.8 \\
24 & $6.0 \times 10^{9}{ }_{\mathrm{a}}^{8}$ & $6.9 \times 10^{8} \mathrm{~b}$ & 3.1 \\
\hline
\end{tabular}

${ }_{\text {ab }}$ Different letters between columns indicate significant differences at a level of 0.05 . 


\subsection{Effect of Ag NPs on the growth of E. coli, L. acidophilus, and B. animalis}

Different concentrations $(0.1,0.4,0.9,1.3 \mathrm{mM})$ of Ag NPs were used to assess their

effects of on E. coli, L. acidophilus, and B. animalis. No significant differences $(P \leq .05)$ between the control and treated samples were observed up to $1.3 \mathrm{mM}$ of Ag NPs for the three bacteria (data not shown).

There are several possible mechanisms of antibacterial activity by Ag NPs. One of them is because of $\mathrm{Ag}^{+}$ions from Ag NPs (Sondi and others 2004; Morones and others 2005; Choi and others 2008). These reported studies showed that Ag NPs released $\mathrm{Ag}^{+}$ions in the presence of oxygen and water (Equation 1).

$4 \mathrm{Ag}+\mathrm{O}_{2}+2 \mathrm{H}_{2} \mathrm{O}=4 \mathrm{Ag}^{+}+4 \mathrm{OH}^{-}$(Equation 1)

After $\mathrm{Ag}^{+}$ions are released from the Ag NPs, there is a possibility that they affect membrane-bound enzyme functions in bacterial cells and facilitate the generation of ROS (McDonnell and others 1999; Pal and other 2007). Also, the electrostatic forces between $\mathrm{Ag}^{+}$ions and the negatively charged cell membrane or wall may result in the inhibition of respiratory chain enzymes, a change in membrane permeability and ultimately cell lysis and death (Ratte 1999; Sambhy and others 2006).

In the case of $E$. coli, the number of cells grew rapidly within $6 \mathrm{~h}$ of incubation using a shaker incubator. Therefore, one of the reasons for the ineffectiveness of Ag NPs on $E$. coli might be that $E$. coli used up all the oxygen in the tube so quickly that there was no chance for Ag NPs to be in contact with oxygen and to allow for release of $\mathrm{Ag}^{+}$ions. Therefore, another set of experiment was performed using the same concentrations of $\mathrm{Ag}$ 
NPs but with larger flasks which could contain more oxygen than the test tubes. The results were very similar to that of the previous experiment in that there was no significant effect of Ag NPs on E. coli (data not shown). Therefore, the higher concentrations $(1.8,2.7,4.6 \mathrm{mM})$ of Ag NPs were used for further experiments. Figure 4.2 shows the growth curves of E. coli, L. acidophilus, and B. animalis with different concentrations of Ag NPs and NP-free solution. Ag NPs at 1.8, 2.7 and 4.6 mM have a significant effect $(P \leq .05)$ on $E$. coli for up to $9 \mathrm{~h}$. As the concentrations of Ag NPs increased to $1.8,2.7$, and $4.6 \mathrm{mM}$, the growth of $E$. coli was more greatly inhibited for up to $10 \mathrm{~h}$ of incubation. After $10 \mathrm{~h}$, their numbers showed no differences when compared to the controls. Compared to E. coli, L. acidophilus and B. animalis showed less inhibitory effects by Ag NPs. The growth curve of treated L. acidophilus and B. animalis showed very similar patterns as those of their controls and NP-free controls. Concentrations of Ag NPs up to $1.8 \mathrm{mM}$ had no significant effects on L. acidophilus and B. animalis. Ag NPs at 2.7 and $4.6 \mathrm{mM}$ showed a significant effect $(P \leq .05)$ on $L$. acidophilus and B. animalis for up to $9 \mathrm{~h}$. No significant effects of Ag NPs after $12 \mathrm{~h}$ of exposure were observed for L. acidophilus and B. animalis. As shown in Tables 4.3, 4.4, and 4.5, all the three strains showed higher reduction numbers of cells between 3 to $6 \mathrm{~h}$ of exposure to Ag NPs. After $9 \mathrm{~h}$ of exposure to Ag NPs, less than 5\% of cell reductions were observed. The mechanisms of the inhibitory effects of Ag NPs on microorganisms are partially known. Some studies (Dragieva and others 1999; Hamouda and others 2000; Dibrov, Dzioba, and Hass 2002) have reported that the positive charge on the $\mathrm{Ag}^{+}$ion is crucial for its antimicrobial activity through the electrostatic attractions between the negatively 

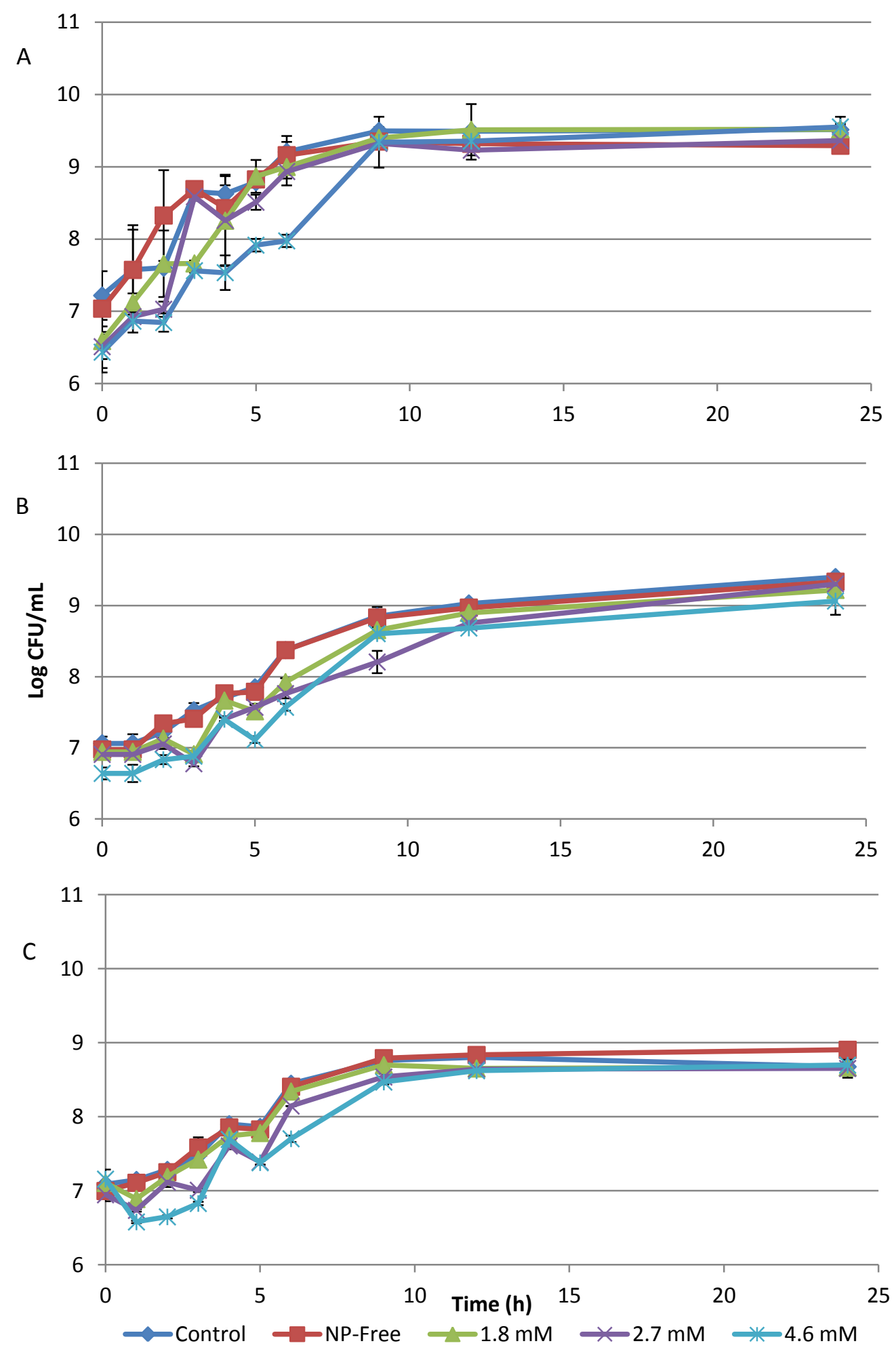

Figure 4.2 Effects of Ag NPs on the growth of E. coli (A), L. acidophilus (B) and B. animals (C). 
charged cell membrane of microorganisms and positively charged Ag NPs. In this study, $L$. acidophilus and B. animalis showed less inhibitory effect by Ag NPs compared to $E$. coli. As explained earlier, Ag NPs release $\mathrm{Ag}^{+}$ions when in the presence of oxygen and water. However, because they are both facultative anaerobes, L. acidophilus and B. animalis were incubated in anaerobic conditions. Hence, there was not enough oxygen available for the $\mathrm{Ag}$ NPs to release $\mathrm{Ag}^{+}$ions. This could explain why these two bacteria were less inhibited by Ag NPs as compared to E. coli. Without oxygen, Ag NPs cannot release $\mathrm{Ag}^{+}$ions which would have affected the growth of the bacterial cells. The slight inhibitory effect on the growth of $L$. acidophilus and B. animalis may be due to the $\mathrm{Ag}$ NPs exposure to oxygen during the preparations and experiments release of $\mathrm{Ag}^{+}$ions. Additionally, compared to Ag NPs, ZnO NPs showed higher inhibitory effect on $L$. acidophilus and B. animalis. This is because $\mathrm{ZnO}$ NPs can release $\mathrm{Zn}^{+}$ions regardless of the presence of oxygen. However, a study by Sondi and Salopek-Sondi (2004) used negatively charged Ag NPs which cannot support the antimicrobial mechanisms of positively charged Ag NPs. Therefore, another possible mechanism as described by Amro and others (2000) can explain the antimicrobial effect of Ag NPs. They suggested that metal depletion may cause the formation of irregularly shaped pits on the outer membrane of cells that can change the membrane permeability and cause leakage of internal cell contents. However, the exact mechanisms of antibacterial property of NPs to different types of bacteria are still not completely understood.

Unlike the results of ZnO NPs on E. coli (Gram negative), which showed higher antimicrobial effects than L. acidophilus and B. animalis (Gram positive) to Ag NPs, 
other studies (Kim and other, 2007; Martinez-Castanon, 2008) showed similar results as those observed in this study. E. coli O157:H7 cells were inhibited by Ag NPs at lower concentrations as compared to S. aureus (Gram positive). Also, the MIC of Ag NPs was lower when testing against $E$. coli than when testing against $S$. aureus. As mentioned above, there is no supporting evidence to explain the species sensitivity in terms of bacterial classification (Gram+ and-) yet. 
Table 4.3 Number of $E$. coli before and after treatment with 4.6 mM of Ag NPs.

\begin{tabular}{cccc}
\hline \multirow{2}{*}{$\begin{array}{c}\text { Time of incubation } \\
\text { (h) }\end{array}$} & \multicolumn{2}{c}{ Number of colonies $(\mathrm{CFU} / \mathrm{mL})$} & \\
\cline { 2 - 3 } & $1.7 \times 10^{7}{ }_{\mathrm{a}}$ & Treatment with & \% of Reduction \\
\hline 0 & $3.8 \times 10^{7}{ }_{\mathrm{a}}$ & $7.3 \times 10^{6}{ }_{\mathrm{b}}$ & 10.8 \\
1 & $4.0 \times 10^{7}{ }_{\mathrm{a}}$ & $7.0 \times 10^{6}{ }_{\mathrm{b}}$ & 9.4 \\
2 & $4.5 \times 10^{8}{ }_{\mathrm{a}}$ & $3.7 \times 10^{7}{ }_{\mathrm{b}}$ & 9.9 \\
3 & $4.2 \times 10^{8}{ }_{\mathrm{a}}$ & $3.4 \times 10^{7}{ }_{\mathrm{b}}$ & 12.6 \\
4 & $6.1 \times 10^{8}{ }_{\mathrm{a}}$ & $8.2 \times 10^{7}{ }_{\mathrm{b}}$ & 12.6 \\
5 & $1.6 \times 10^{9}{ }_{\mathrm{a}}$ & $9.4 \times 10^{8}{ }_{\mathrm{b}}$ & 9.9 \\
6 & $3.1 \times 10^{9}$ & $2.2 \times 10^{9}$ & 13.3 \\
9 & $3.1 \times 10^{9}$ & $2.3 \times 10^{9}$ & 1.6 \\
12 & $3.3 \times 10^{9}$ & $3.6 \times 10^{9}$ & 1.4 \\
24 & & & -0.4 \\
\hline
\end{tabular}

${ }_{\mathrm{ab}}$ Different letters between columns indicate significant differences with a significant level of 0.05 . 
Table 4.4 Number of L. acidophilus before and after treatment with $4.6 \mathrm{mM}$ of Ag NPs.

\begin{tabular}{cccc}
\hline \multirow{2}{*}{$\begin{array}{c}\text { Time of incubation } \\
\text { (h) }\end{array}$} & \multicolumn{2}{c}{ Number of colonies (CFU/ mL) } & \\
\cline { 2 - 3 } & Control & $\begin{array}{c}\text { Treatment with } \\
\text { Ag NPs }\end{array}$ & \\
\hline 0 & $1.2 \times 10^{7}$ & $4.4 \times 10^{6}$ & 6.3 \\
1 & $1.3 \times 10^{7}$ & $4.5 \times 10^{6}$ & 6.3 \\
2 & $1.7 \times 10^{7}$ & $6.8 \times 10^{6}$ & 5.6 \\
3 & $3.4 \times 10^{7}{ }_{\mathrm{a}}$ & $7.6 \times 10^{7}{ }_{\mathrm{b}}$ & 9.3 \\
4 & $5.1 \times 10^{7}$ & $2.5 \times 10^{7}$ & 4.1 \\
5 & $7.1 \times 10^{7}{ }_{\mathrm{a}}$ & $1.3 \times 10^{7}{ }_{\mathrm{b}}$ & 10.3 \\
6 & $2.4 \times 10^{8}{ }_{\mathrm{a}}$ & $3.7 \times 10^{7} \mathrm{~b}$ & 10.6 \\
9 & $7.1 \times 10^{8}$ & $4.0 \times 10^{8}$ & 2.8 \\
12 & $1.1 \times 10^{9}$ & $4.8 \times 10^{8}$ & 3.9 \\
24 & $2.5 \times 10^{9}$ & $1.2 \times 10^{9}$ & 3.7 \\
\hline
\end{tabular}

${ }_{a b}$ Different letters between columns indicate significant differences at a level of 0.05 . 
Table 4.5 Number of B. animalis before and after treatment with $4.6 \mathrm{mM}$ of Ag NPs.

\begin{tabular}{cccc}
\hline \multirow{2}{*}{$\begin{array}{c}\text { Time of incubation } \\
\text { (h) }\end{array}$} & \multicolumn{2}{c}{ Number of colonies $(\mathrm{CFU} / \mathrm{mL})$} & \\
\cline { 2 - 3 } & $1.2 \times 10^{7}$ & Treatment with ZnO & \% of Reduction \\
\hline 0 & $1.4 \times 10^{7}{ }_{\mathrm{a}}$ & $3.8 \times 10^{6}{ }_{\mathrm{b}}$ & -0.9 \\
1 & $1.9 \times 10^{7}{ }_{\mathrm{a}}$ & $4.5 \times 10^{6}{ }_{\mathrm{b}}$ & 7.9 \\
2 & $3.0 \times 10^{7}{ }_{\mathrm{a}}$ & $6.7 \times 10^{6}{ }_{\mathrm{b}}$ & 8.7 \\
3 & $8.0 \times 10^{7}$ & $5.0 \times 10^{7}$ & 8.6 \\
4 & $7.3 \times 10^{7}$ & $2.4 \times 10^{7}$ & 2.6 \\
5 & $2.8 \times 10^{8} \mathrm{a}$ & $5.1 \times 10^{7}{ }_{\mathrm{b}}$ & 6.1 \\
6 & $5.8 \times 10^{8}$ & $3.0 \times 10^{7}$ & 8.8 \\
9 & $6.4 \times 10^{8}$ & $4.2 \times 10^{8}$ & 3.3 \\
12 & $4.8 \times 10^{8}$ & $5.0 \times 10^{9}$ & 2.0 \\
24 & & & -0.2
\end{tabular}

${ }_{\text {ab }}$ Different letters between columns indicate significant differences at a level of 0.05 . 


\subsection{Characterization of $\mathrm{ZnO}$ and Ag NPs}

The size and morphology of $\mathrm{ZnO}$ and Ag NPs were determined by TEM. The original $\mathrm{ZnO}$ NPs suspensions were diluted with ultra purified water and observed under TEM (Figure 4.3). Most of ZnO NPs were in either round or oval shape with an average size of $77.9 \mathrm{~nm}$. The software ImageJ was used to analyze the sized of NPs. Figure 4.4 showed the histogram of the size distribution of $\mathrm{ZnO} \mathrm{NPs,} \mathrm{and} \mathrm{the} \mathrm{majority} \mathrm{of} \mathrm{ZnO}$ NPs measured fell in the range of 60 to $80 \mathrm{~nm}$ in diameter. $\mathrm{ZnO}$ NPs may be present in the form of agglomerates due to synthetic processing (Zhang and others, 2007). Therefore, ultrasonication and dispersants, such as polyethylene glycol (PEG), polyvinylpyrolidone (PVP) and bovine serum albumin (BSA) are often used to disintegrate NPs agglomerates (Brayner and others, 2006). However, as shown in Figure 4.3, ZnO NPs were relatively well dispersed with slight agglomeration in ultra-purified water without sonification or dispersant. Also, a shaking incubator was used to avoid the aggregation of ZnO NPs in the broth. 


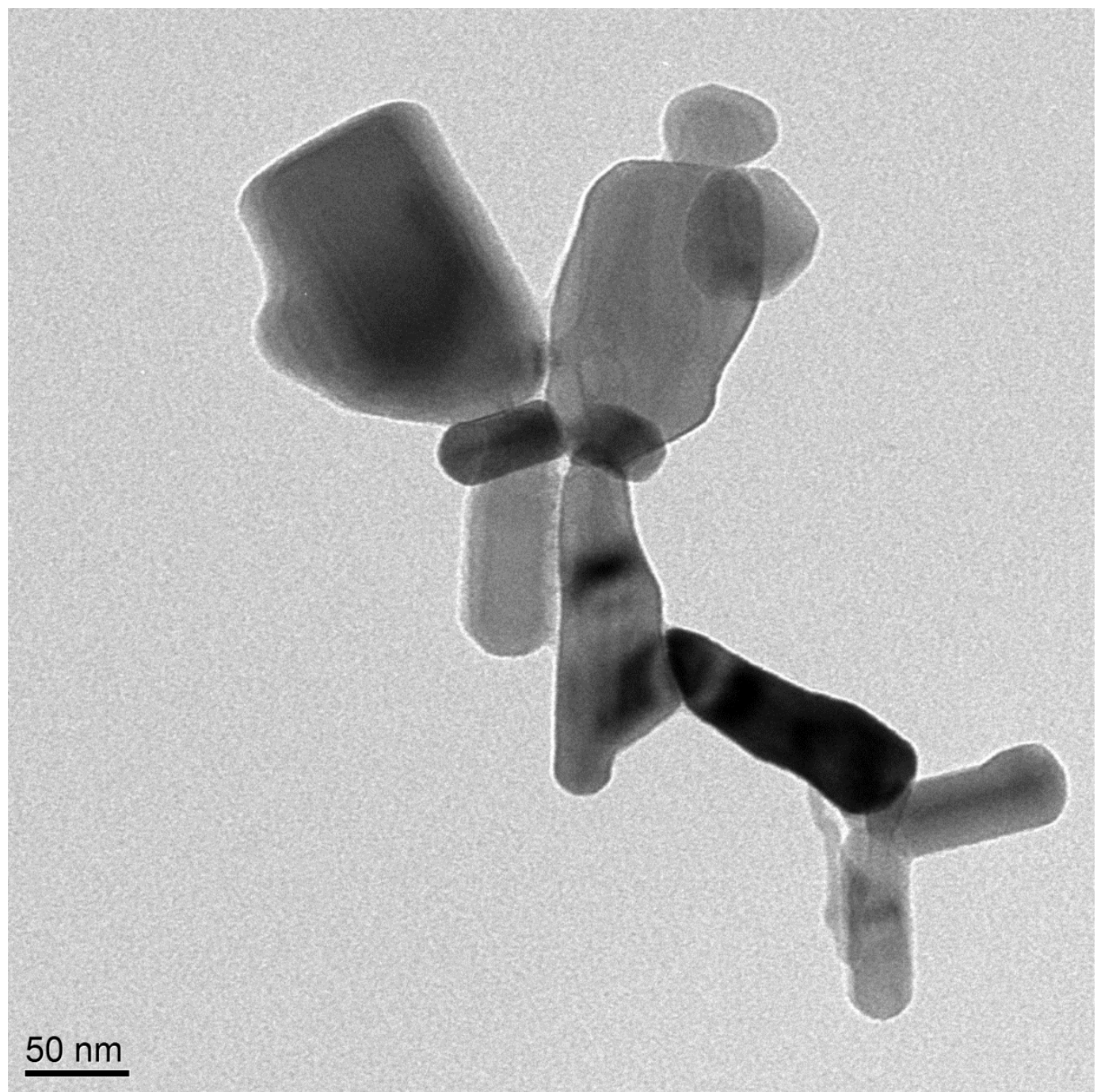

Fig. 4.3 TEM image of $\mathrm{ZnO}$ NPs diluted with ultra-purified water. 


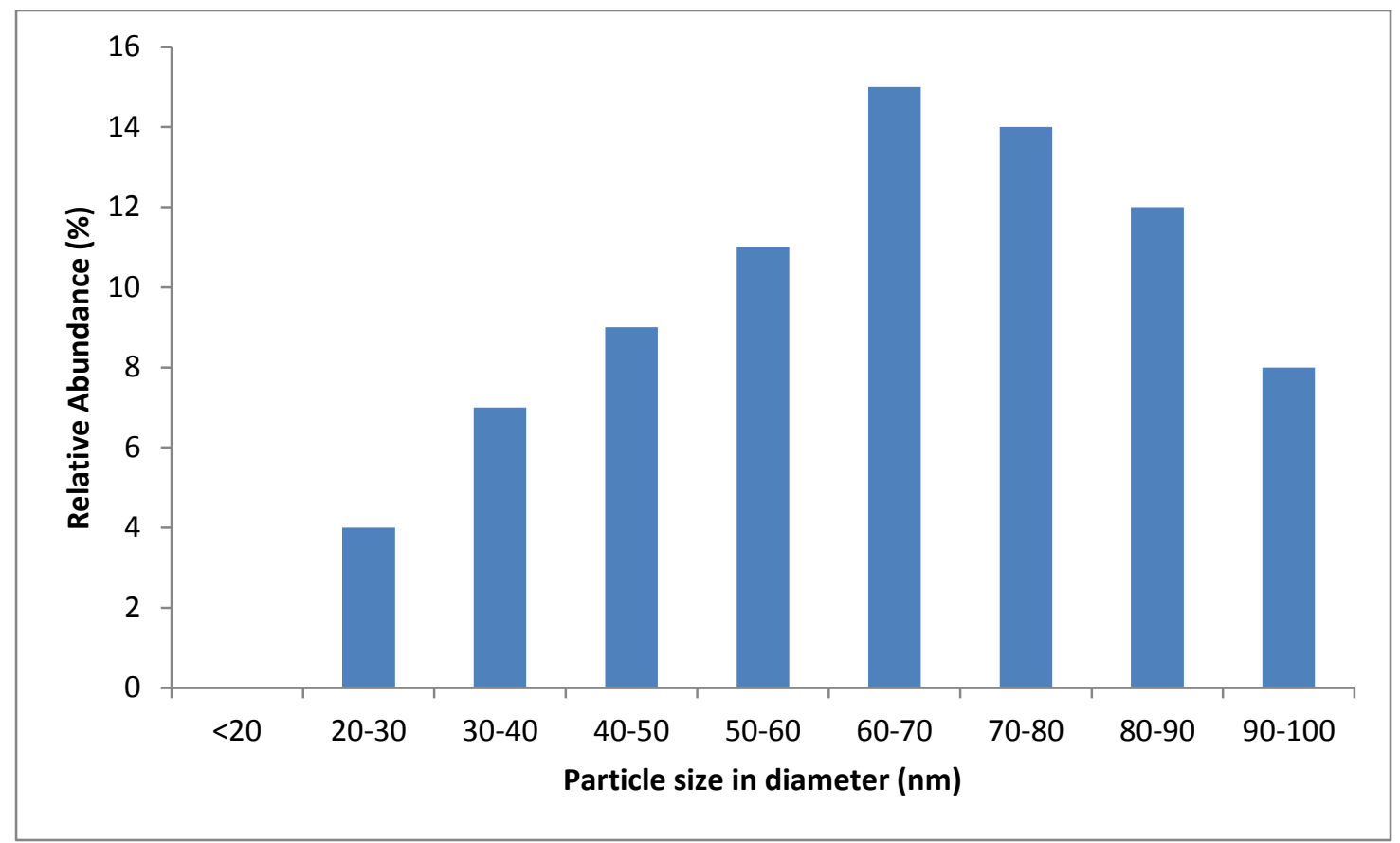

Fig. 4.4 Size distribution of $\mathrm{ZnO}$ NPs with an average size of $70.9 \mathrm{~nm}$ in diameter. 
The Ag NPs synthesized by using a chemical reduction method were observed under TEM (Figure 4.4). The shapes of Ag NPs observed under TEM were uniformly spherical and well dispersed. The majority of the Ag NPs measured fell in the range of 30 to $50 \mathrm{~nm}$ in diameter with an average size of $40.2 \mathrm{~nm}$, and a histogram of the size distribution of Ag NPs is shown in Figure 4.5.

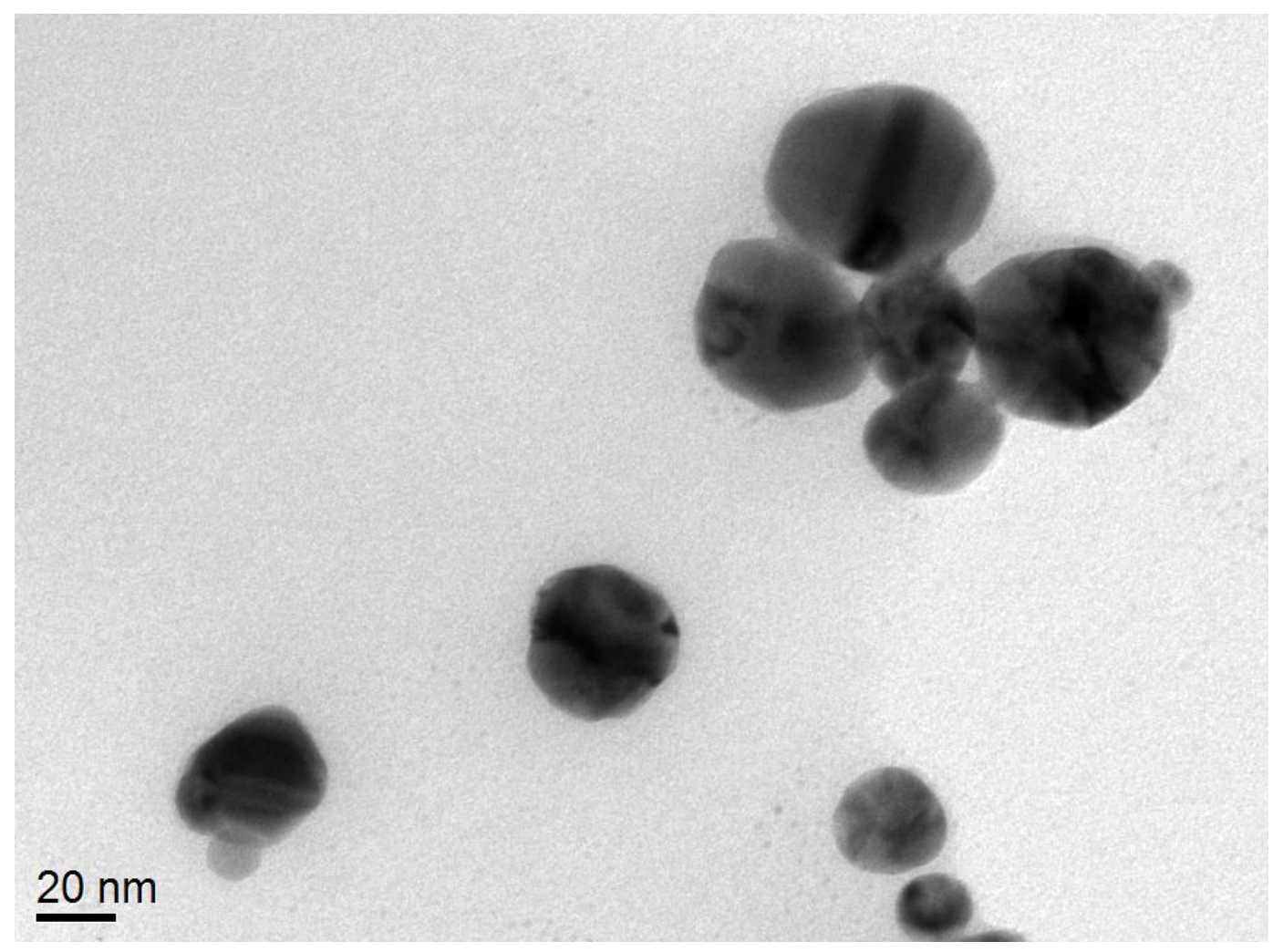

Fig. 4.5 TEM image of Ag NPs. 


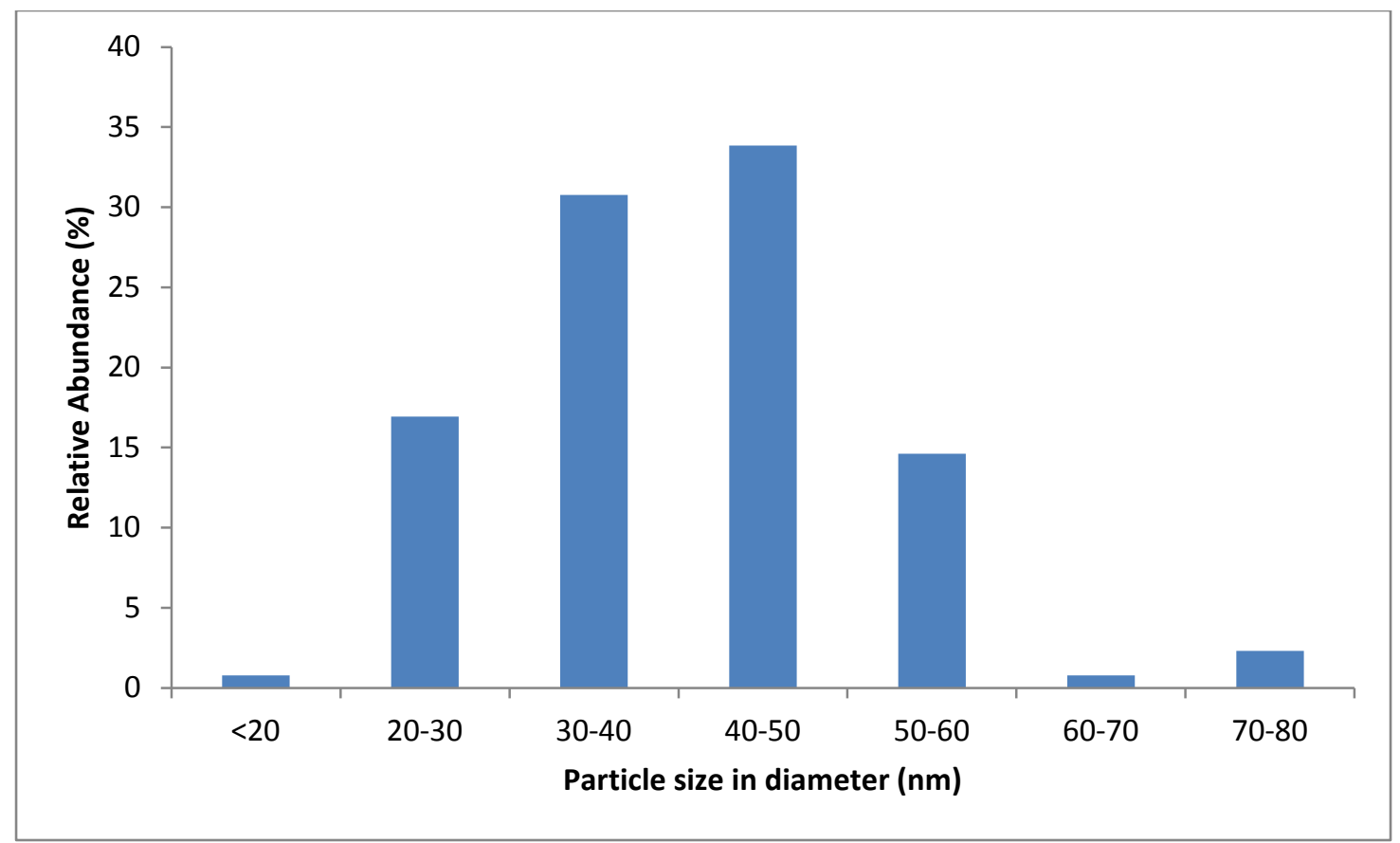

Fig. 4.6 Size distribution of Ag NPs with an average size of $40.2 \mathrm{~nm}$ in diameter. 


\subsection{Morphological test of bacteria cells}

\subsubsection{Treated with $\mathrm{ZnO}$ NPs}

The SEM and TEM images (Figures 4.7 and 4.8) of E. coli, L. acidophilus, and B. animalis incubated in respective broth medium for $10 \mathrm{~h}$, with and without the presence of $20 \mathrm{mM}$ of $\mathrm{ZnO}$ were analyzed.

As shown in Figures 4.7A and 4.7B, no significant changes in bacterial morphology (e.g. size, shape, appearance, etc) were observed after $\mathrm{ZnO}$ NPs treatment for $10 \mathrm{~h}$. Also, $\mathrm{ZnO}$ NPs were observed to adhere to the $E$. coli cells (Figure 4.7B). The sizes of ZnO NPs attached to bacterial cells appeared larger and clustered as compared to those shown in the corresponding TEM image (Figure 4.3). This may be due to agglomeration of $\mathrm{ZnO}$ NPs during the incubation time. Figures 4.8A and 4.8B are TEM images that allow direct visualization of intracellular morphological changes of bacterial cells before and after treatment with ZnO NPs. Figure 4.8A shows the intracellular structures of E. coli control sample. The bacterial cells were normal in size with intact intracellular structures and well-maintained intracellular contents. Deformations of intracellular structures of bacterial cells were observed in Figure 4.8B. However, not all cells were damaged which could explain the result of the previous experiment where no effect of $\mathrm{ZnO}$ NPs on $E$. coli was demonstrated. 


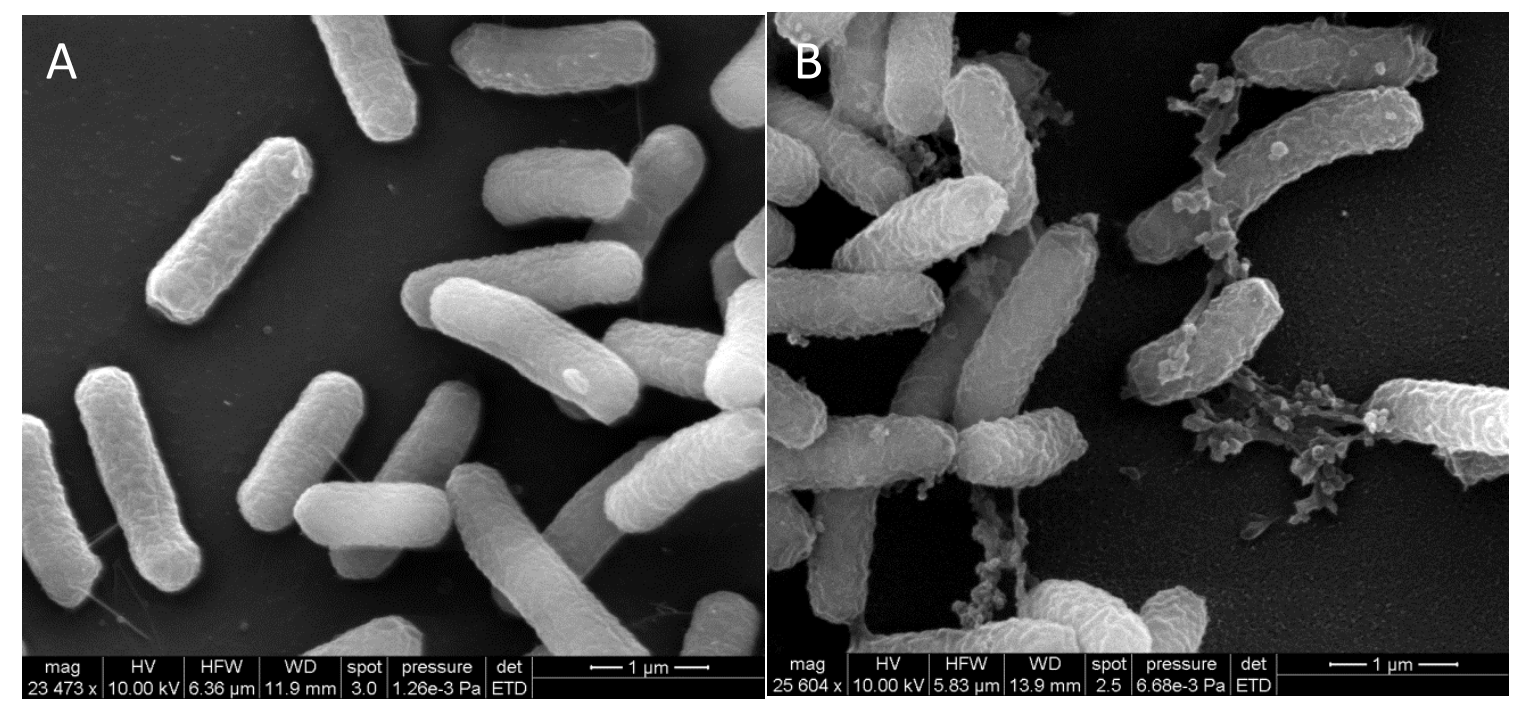

Figure 4.7 SEM images of $E$. coli without the treatment of $\mathrm{ZnO}$ NPs (A) and with 20 mM ZnO NPs (B).

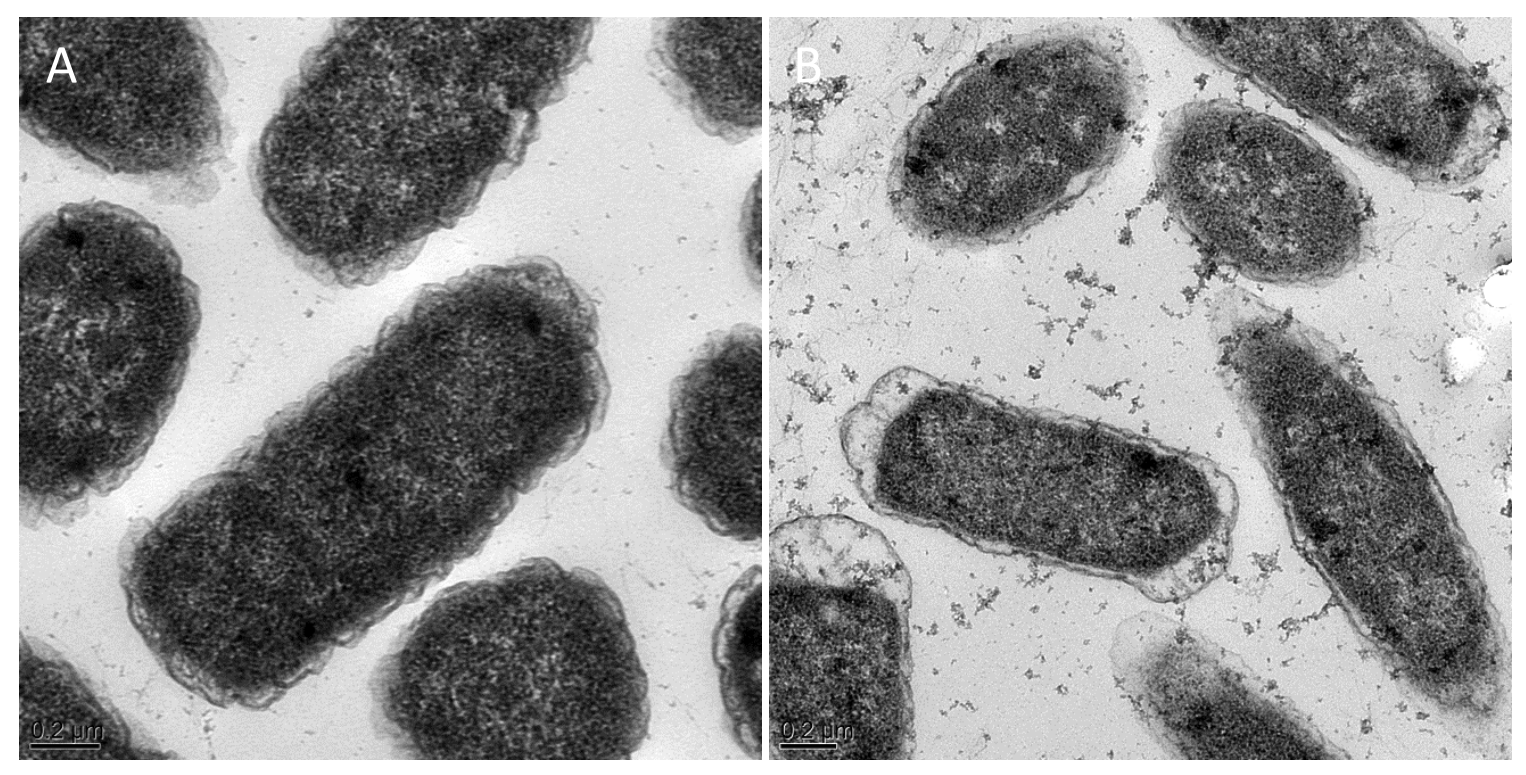

Figure 4.8 TEM images of E. coli without the treatment of ZnO NPs (A) and with 20 $\mathrm{mM} \mathrm{ZnO}$ NPs (B). 
Figures 4.9 and 4.10 are SEM and TEM images of L. acidophilus before and after treatment of $\mathrm{ZnO}$ NPs. As shown in Figure 4.9A (control) and 4.9B (treated), obvious changes in bacterial morphology were observed after treatment with ZnO NPs. ZnO NPs adhered to the cells and deformed the cell morphology into a spiral shape. Many spiral or twisted cells were found in the sample treated with ZnO NPs. TEM images (Figure 4.10A and 4.10B) show morphological changes of intracellular of L. acidophilus. No damaged cells and very similar shape (rod-shape) of cells as shown in the SEM image were observed in the control sample (Figure 4.10A). On the contrary, treated samples (Figure 4.10B) were clearly damaged by ZnO NPs. The membranes of bacterial cells and intracellular structures were deformed. B. animalis showed very similar morphological changes as L. acidophilus (Figure 4.11, 4.12). Both SEM and TEM images showed significant differences between the external appearance and intracellular structures of bacterial cells between the control and treated samples. Many deformed cells and spiral shaped cells, were observed in the treated samples. Damaged cells in the treated samples indicated leakage of cell contents. The results of the effect of ZnO NPs on L. acidophilus and $B$. animalis can be explained by the damages of intracellular structures observed in Figure $4.10 \mathrm{~B}$ and $4.12 \mathrm{~B}$. 


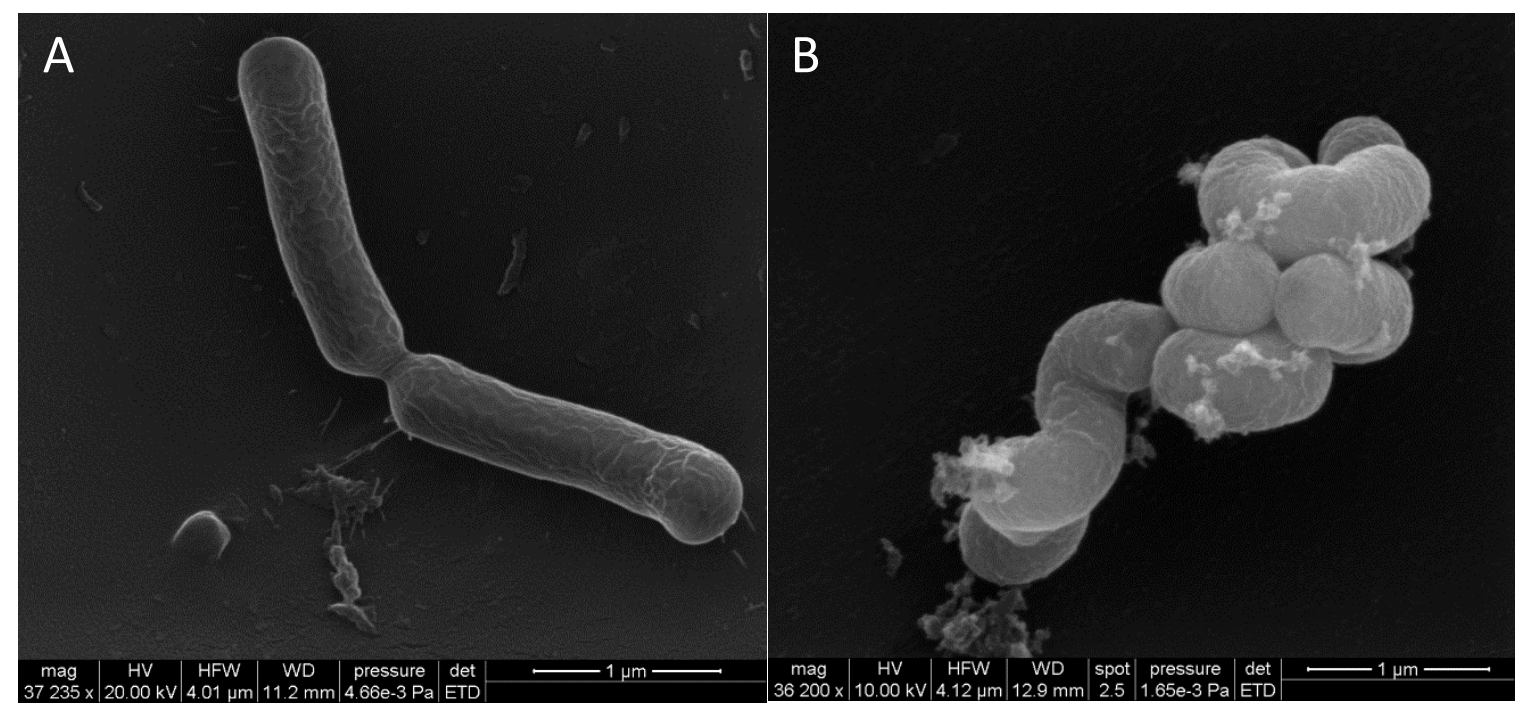

Figure 4.9 SEM images of L. acidophilus without the treatment of ZnO NPs (A) and with $20 \mathrm{mM} \mathrm{ZnO}$ NPs (B).

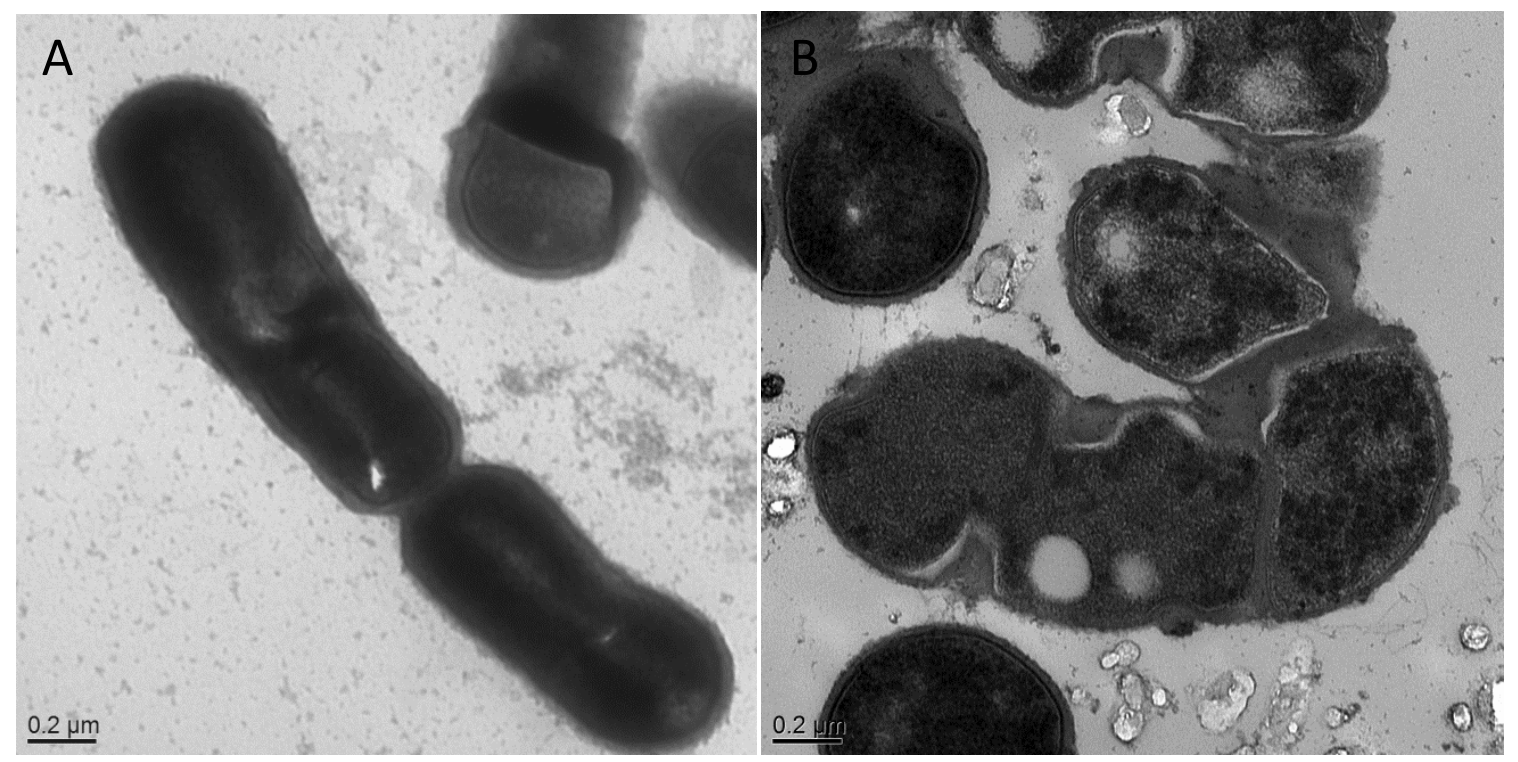

Figure 4.10 TEM images of L. acidophilus without the treatment of ZnO NPs (A) and with $20 \mathrm{mM} \mathrm{ZnO}$ NPs (B). 


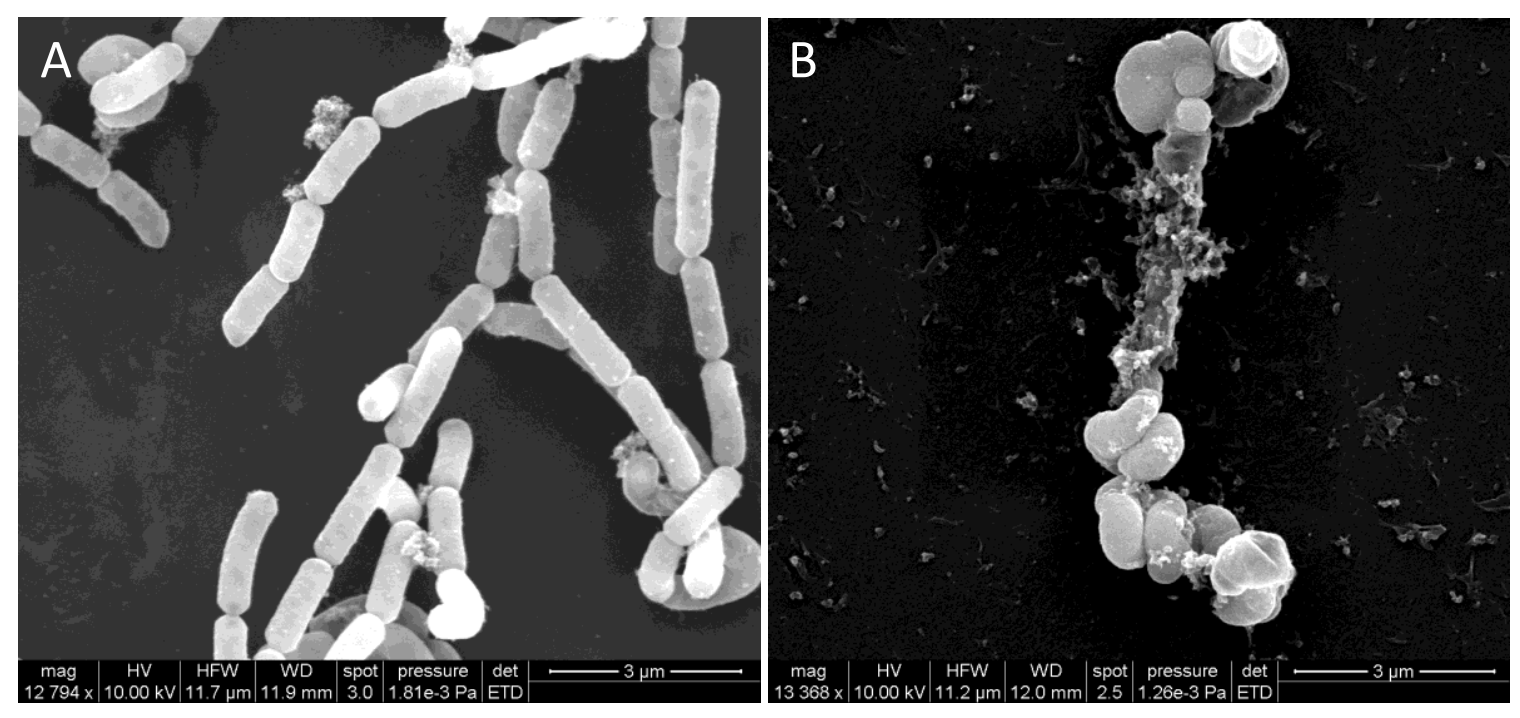

Figure 4.11 SEM images of B. animalis without the treatment of ZnO NPs (A) and with $20 \mathrm{mM} \mathrm{ZnO}$ NPs (B).

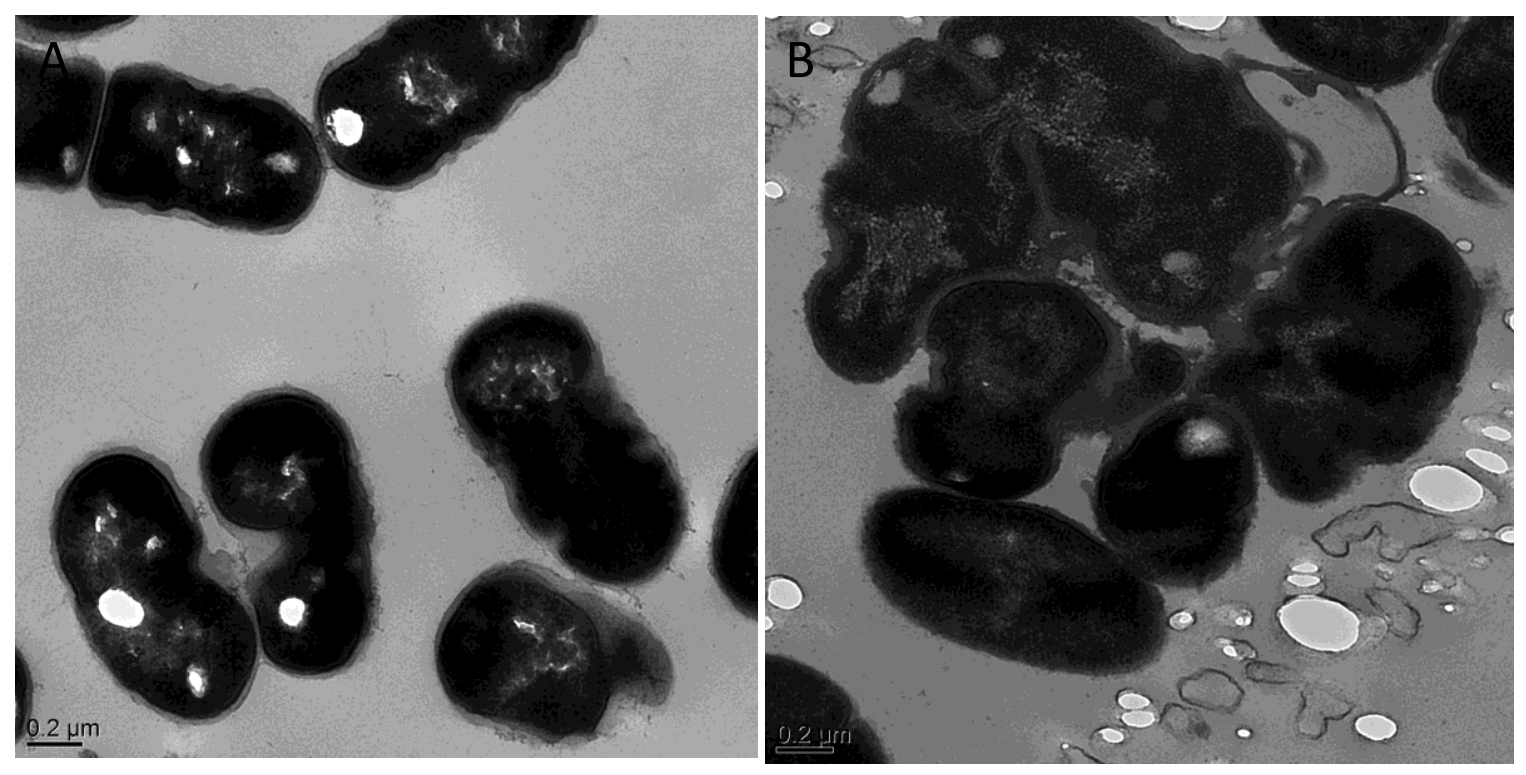

Figure 4.12 TEM images of $B$. animalis without the treatment of $\mathrm{ZnO}$ NPs (A) and with $20 \mathrm{mM} \mathrm{ZnO}$ NPs (B). 
Energy dispersive spectroscopy (EDS) is a common technique for analysis of the elemental composition of a specimen. It is also capable of generating a map of multiple chemical elements of interest at specifically pointed spots. EDS coupled with SEM were used for elemental analysis and it was effective in locating and identifying NPs attached to the bacterial cells.

Figure 4.13 shows SEM-EDS elemental analysis of $\mathrm{ZnO}$ NPs attached to $E$. coli cells. Control cells and $\mathrm{ZnO}$ NPs attached to cells were spotted to analyze the elements. Three spots were selected in each sample to analyze the elements. Results showed that no $\mathrm{Zn}$ elements were identified in the control cells, Figure 4.13A, which was as expected. $\mathrm{Zn}$ elements were observed in samples treated with ZnO NPs (Figure 4.13B and 4.13C) which indicated the presence of $\mathrm{ZnO}$ NPs. Also, relatively large amounts of platinum elements were observed in all samples. This is due to the thin layer of platinum coating to reduce the charges when observing under SEM. 


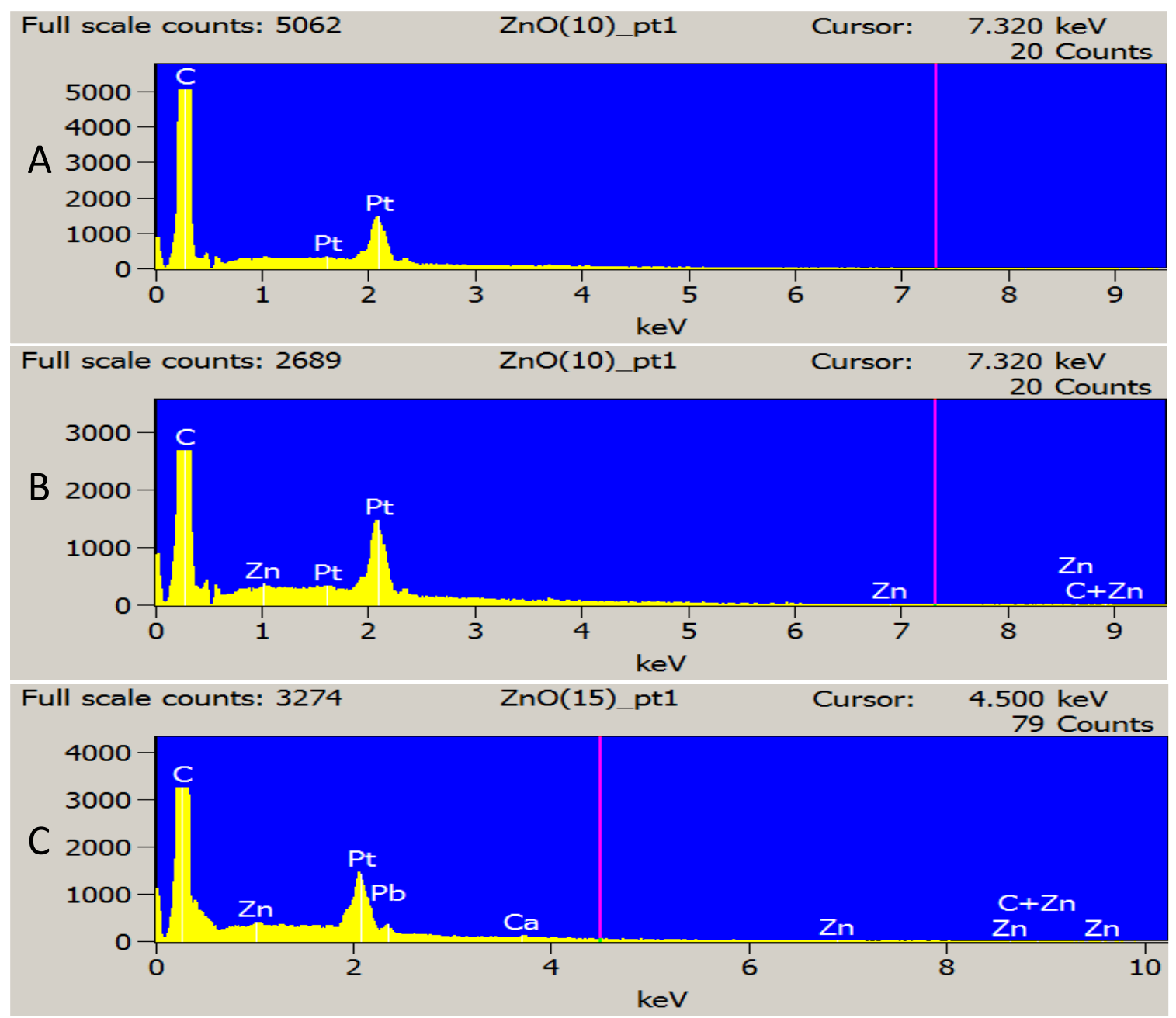

Figure 4.13 Energy-dispersive X-ray spectroscopy spectrum of E. coli without the treatment of ZnO NPs (A), with $20 \mathrm{mM}$ ZnO NPs (B) and B. animalis with $20 \mathrm{mM} \mathrm{ZnO}$ NPs $(\mathrm{C})$. 


\subsubsection{Treated with Ag NPs}

As shown in Tables 4.3, 4.4, and 4.5, bacterial strains exposed to Ag NPs for $6 \mathrm{~h}$ showed the highest antimicrobial effect. Therefore, SEM and TEM images of E. coli, $L$.

acidophilus, and B. animalis incubated in the respective broth medium for $6 \mathrm{~h}$, with and without the presence of $4.6 \mathrm{mM}$ of Ag NPs, were observed.

Figures 4.14A and 4.14B showed SEM images of $E$. coli before and after treatment with Ag NPs. As shown in Figure 4.14A and 4.14B, no significant changes in the external appearance of the cells were observed after treatment with Ag NPs for 6 h. Ag NPs were attached to bacterial cells (Figure 4.14B) in clusters instead of a single particle, as shown in Figure 4.5. Similar agglomeration was observed in ZnO NPs too. Figure 4.15A showed intracellular structures of the $E$. coli control sample. The bacterial cells were normal in size with intact intracellular structures and well-organized intracellular contents.

However, deformation of cell membrane and intracellular structure were observed in Figure 4.15B. Bacterial cells were surrounded by Ag NPs and null bacterial cells were found in bacterial sample treated with Ag NPs, indicating that intracellular contents had leaked from cells due to damage to the cell membrane. 


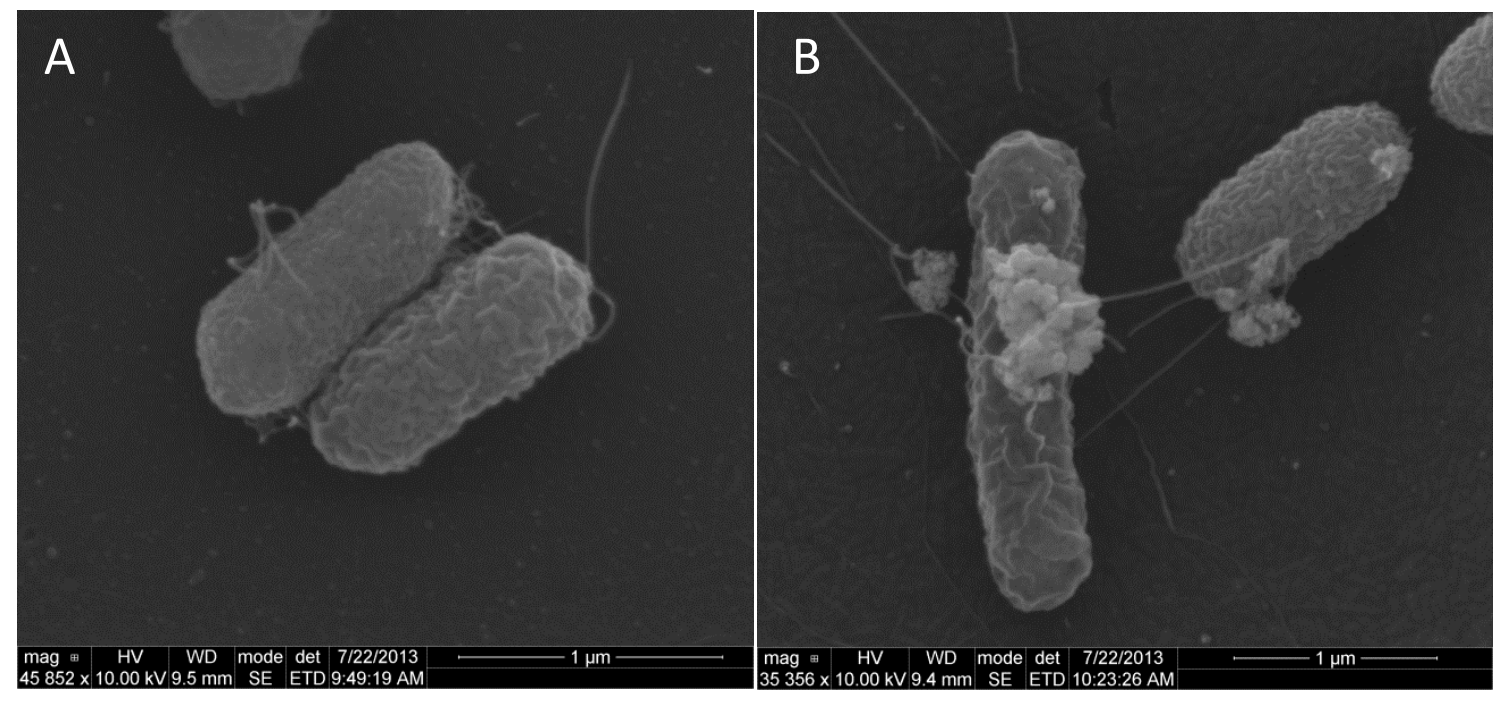

Figure 4.14 SEM images of E. coli without the treatment of Ag NPs (A) and with 4.6 $\mathrm{mM}$ Ag NPs (B).

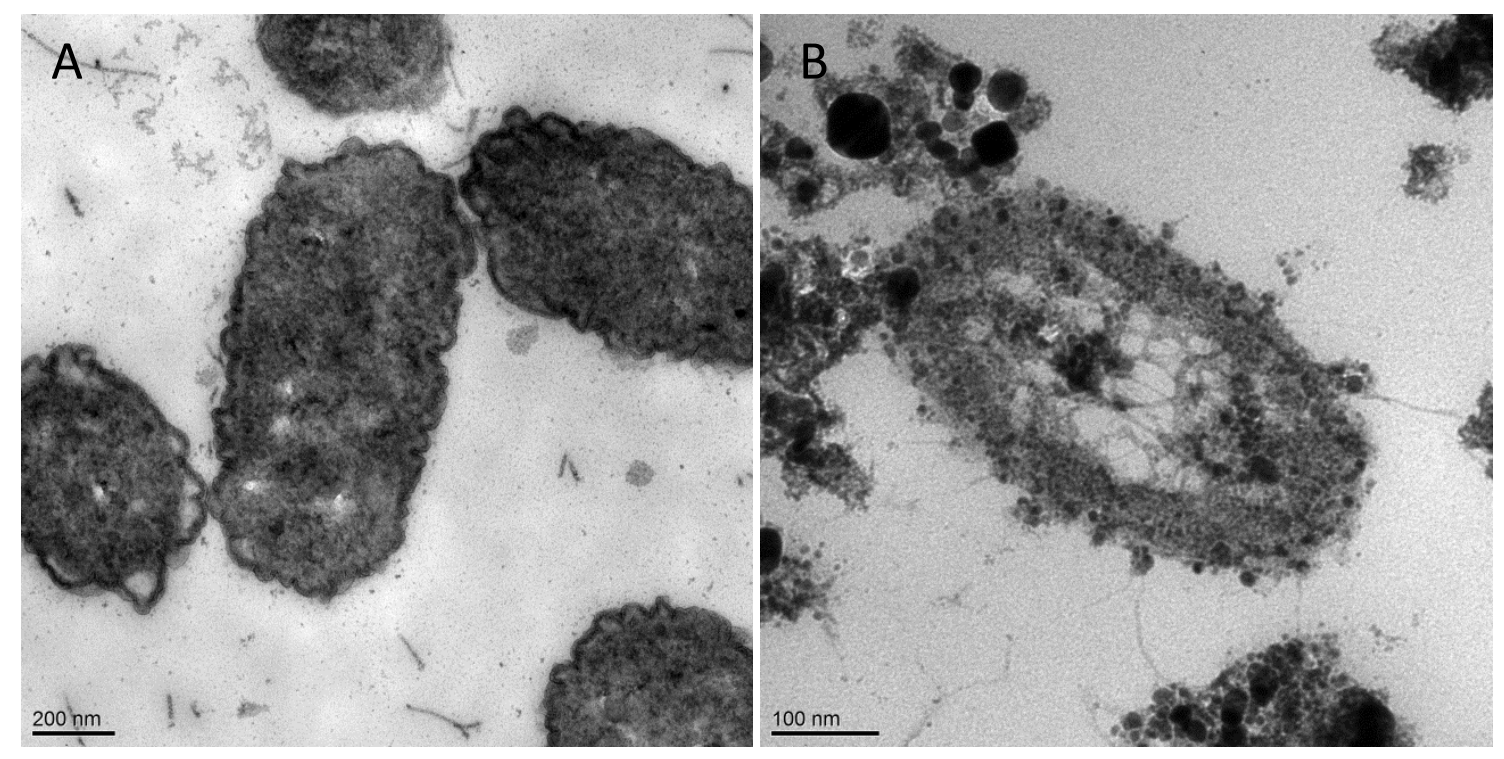

Figure 4.15 TEM images of E. coli without the treatment of Ag NPs (A) and with 4.6 $\mathrm{mM}$ Ag NPs (B). 
The SEM images of L. acidophilus before and after treatment with Ag NPs are shown in Figure 4.16. Very similar morphology of cells was observed for B. animalis samples (Figure 4.18). As shown in Figure 4.16A (control) and 4.16B (treated), no significant changes in bacterial morphology were observed before and after treatment with Ag NPs. However, TEM images of L. acidophilus shown in Figure 4.17 showed differences between treated and untreated cells. Unlike the control sample, treated samples showed distortion of cell membranes and leakage of internal contents of cells. However, not all cells were damaged, there were still many cells in normal size with intact intracellular structures and well-organized intracellular contents. The results in Figure 4.2B, compared with the plate count number of about $10^{7} \mathrm{CFU} / \mathrm{mL}$, which is only $1 \log \mathrm{CFU} . \mathrm{mL}$ less than the control shown previously are supportive of one another, which show. This indicates not all cells were affected by Ag NPs and resulting leakage of internal contents did not occur with all the cells. 


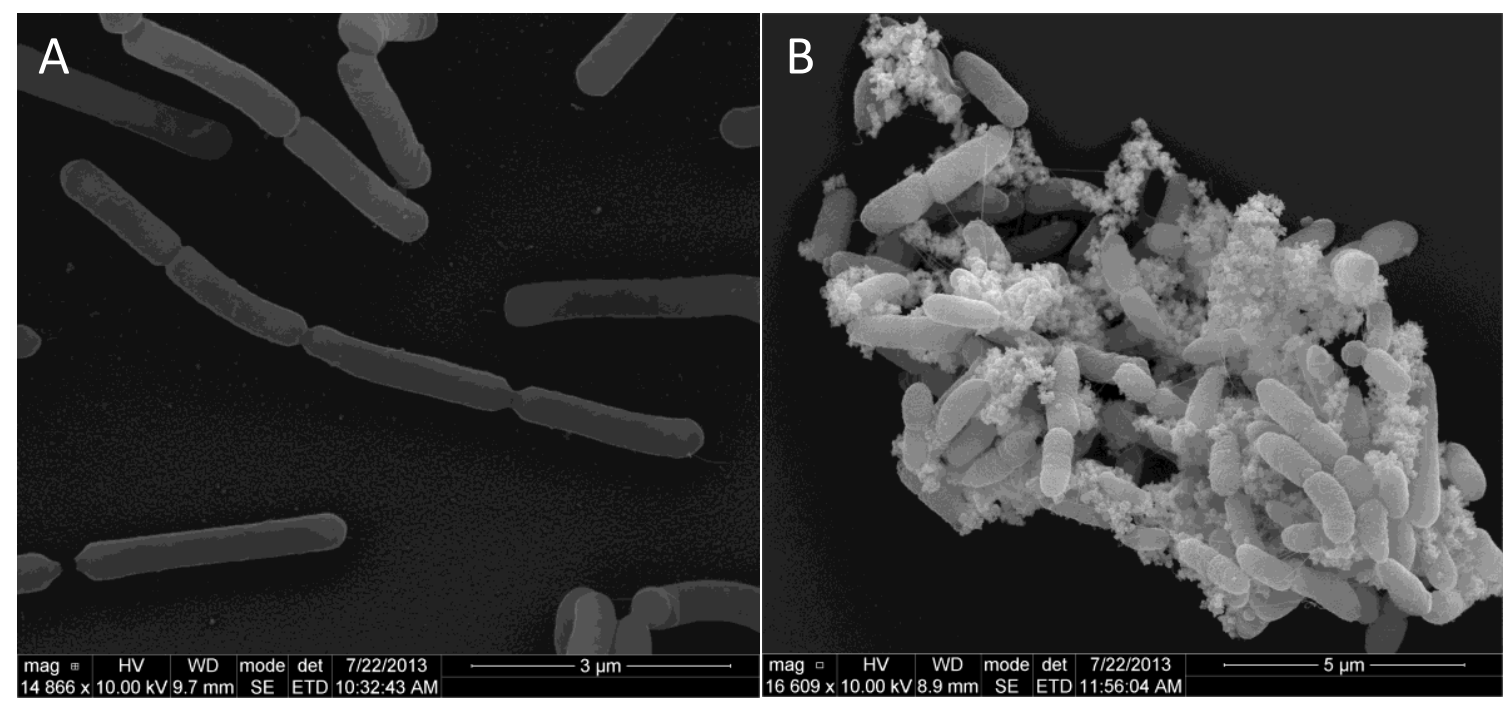

Figure 4.16 SEM images of L. acidophilus without the treatment of Ag NPs (A) and with 4.6 mM Ag NPs (B).

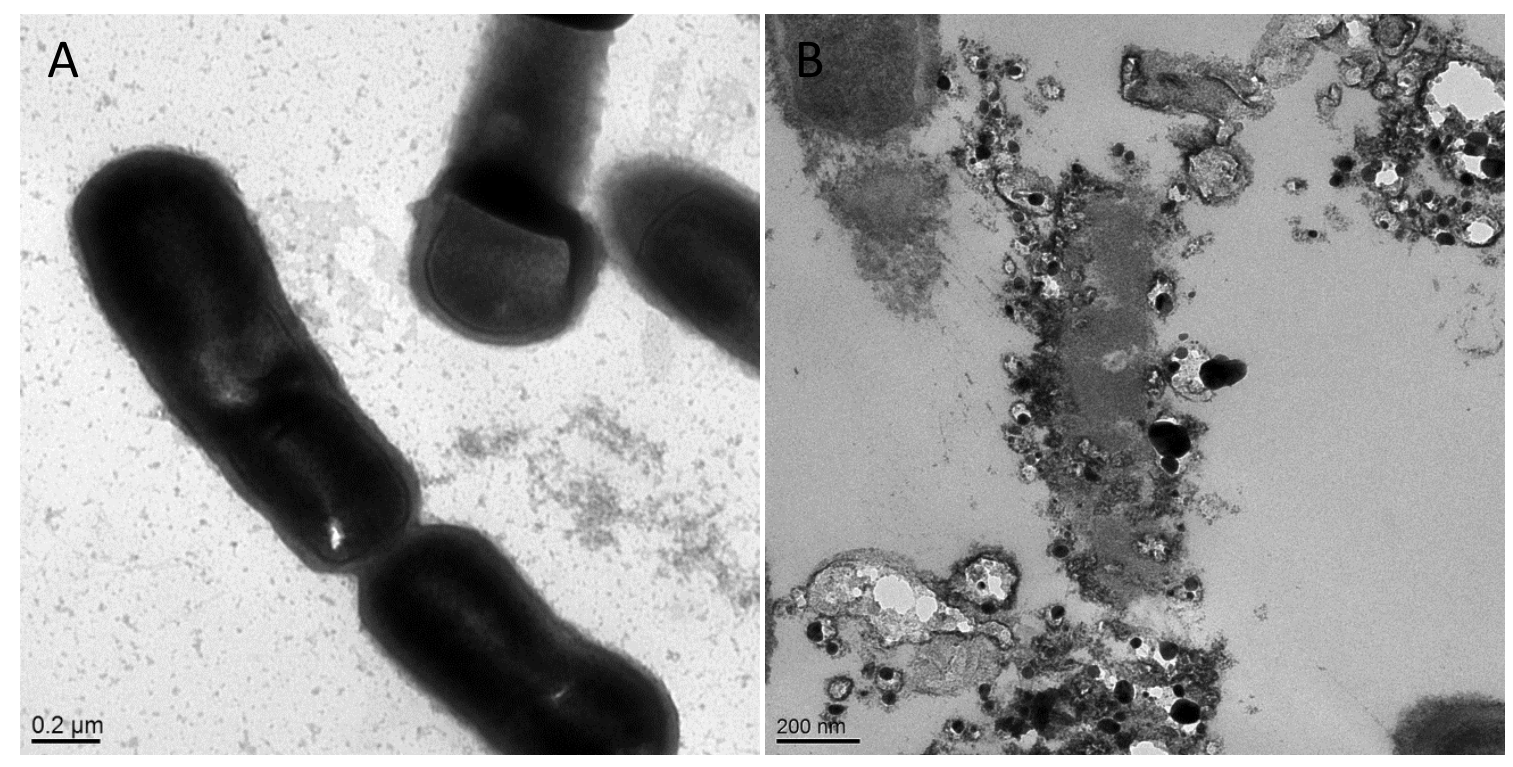

Figure 4.17 TEM images of L. acidophilus without the treatment of Ag NPs (A) and with 4.6 mM Ag NPs (B). 


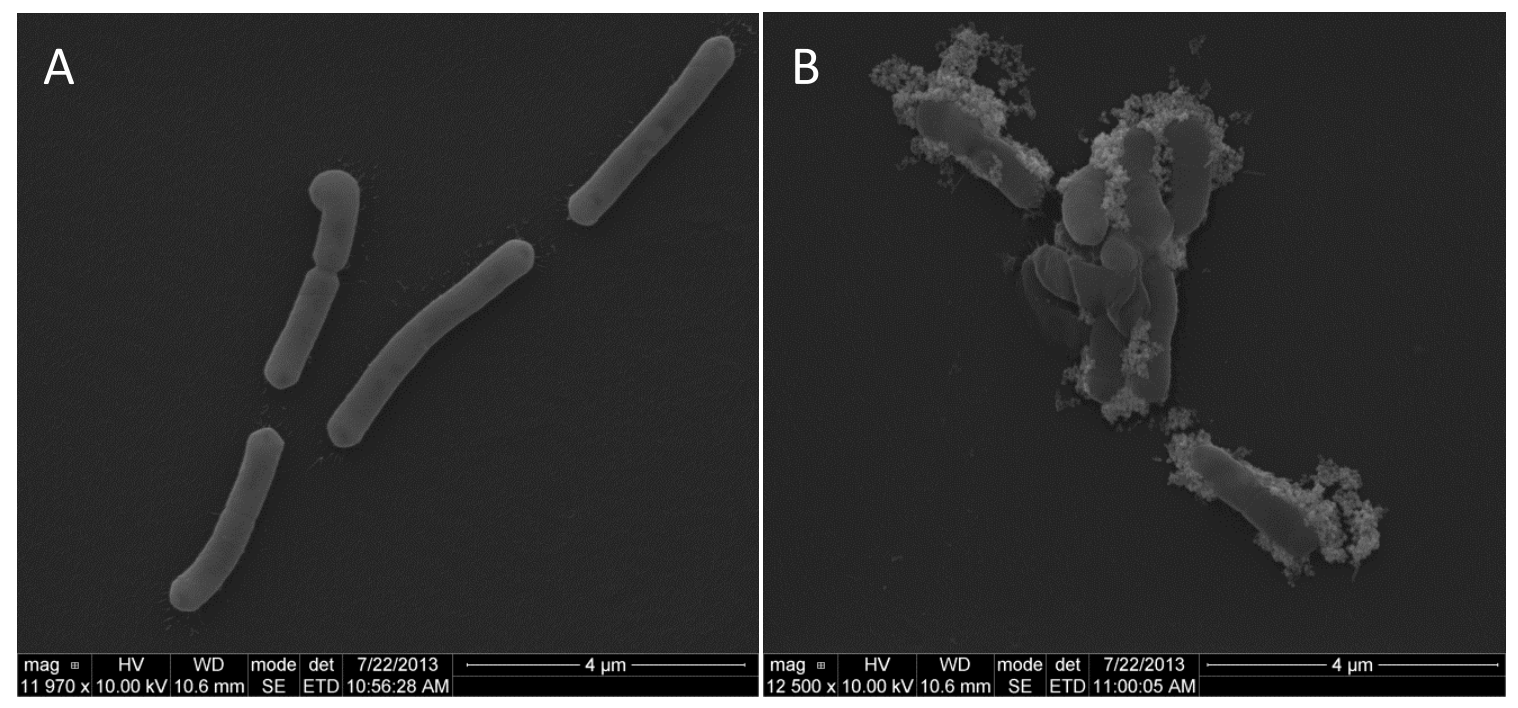

Figure 4.18 SEM images of $B$.animalis without the treatment of Ag NPs (A) and with 4.6 mM Ag NPs (B).
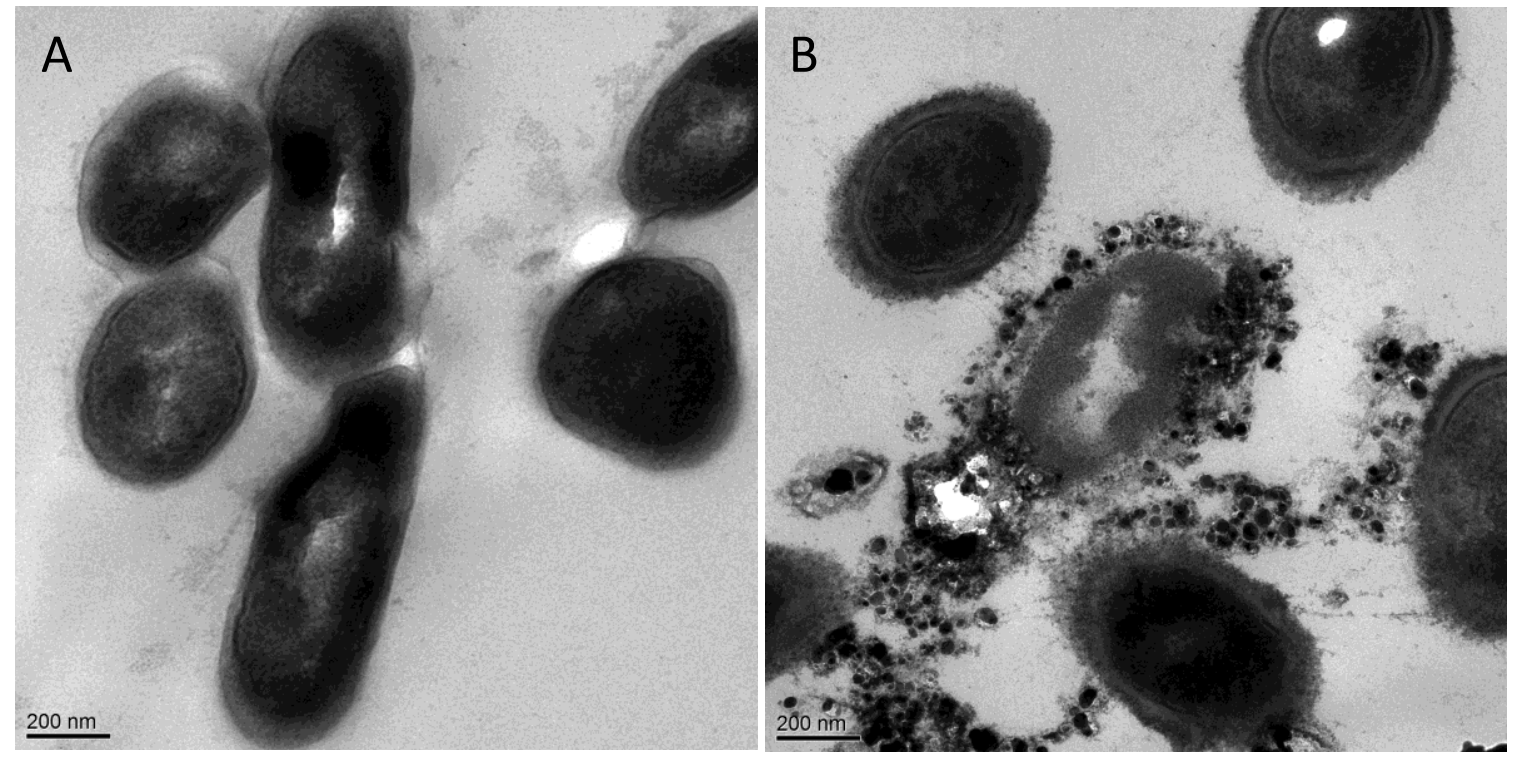

Figure 4.19 TEM images of $B$.animalis without the treatment of Ag NPs (A) and with 4.6 mM Ag NPs (B). 
The results of the SEM-EDS elemental analysis of Ag NPs are shown in Figure 4.20.

Like ZnO NPs samples, three spots were selected in each sample to analyze the elements. No Ag elements were observed in all control samples (Figure 4.20A), while Ag elements were identified in all treated samples (Figure 4.20B, 4.20C). The presence of other element such as silicon ( $\mathrm{Si}$ ) was unexpected, which was most likely contributed by the pre-treatment of the SEM specimens, the sample holder or contamination during the preparation. 


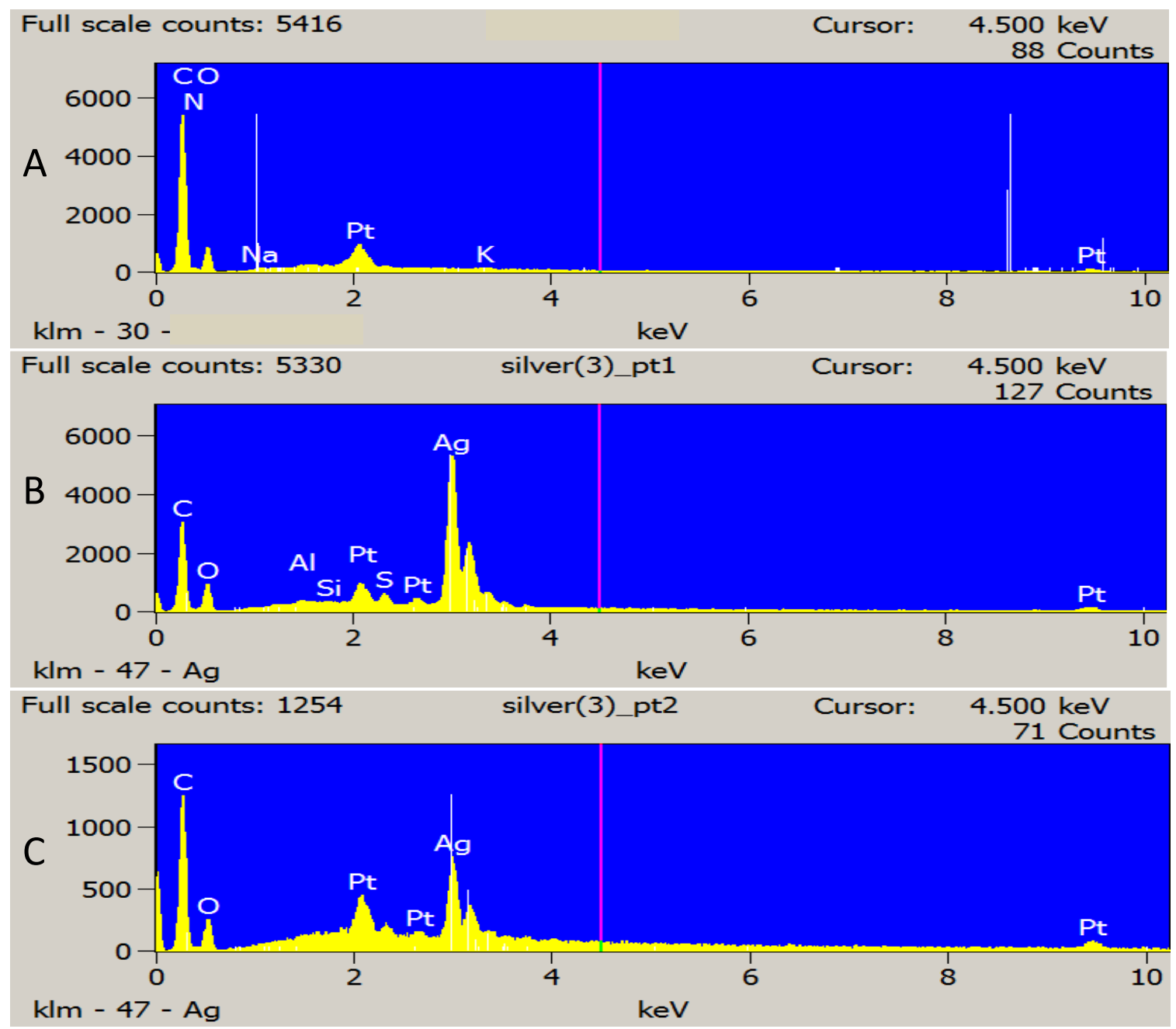

Figure 4.20 Energy-dispersive X-ray spectroscopy spectrum of L.acidophilus without the treatment of Ag NPs (A), with 4.6 mM Ag NPs (B), B. animails with $4.6 \mathrm{mM} \mathrm{Ag} \mathrm{NPs}$ (C). 


\subsection{Determination of membrane leakage}

To determine membrane leakage, a UV-visible spectrophotometer was used to monitor the absorbance at wavelength of $260 \mathrm{~nm}$ (DNA absorbance). The absorbance is related to the leakage amount of intracellular DNAs. Figure 4.21 shows the absorbance of bacterial strains after treatment of $\mathrm{ZnO}$ NPs for $10 \mathrm{~h}$. For all three bacteria, the absorbance at 260 $\mathrm{nm}$ shows a slight increase after $10 \mathrm{~h}$ of exposure to $\mathrm{ZnO}$ NPs. Higher concentrations of $\mathrm{ZnO}$ NPs resulted in a higher absorbance. Figure 4.22 showed the absorbance of bacterial strains after treatment of Ag NPs for $6 \mathrm{~h}$. The results were similar to the ZnO NPs results. Absorbance at $260 \mathrm{~nm}$ of all three bacteria increased slightly as compared to the control. The absorbance increased due to the leakage of nucleic acids from bacterial cells when their cell membranes are damaged. However, there were no significant differences $(P$ $\leq .05)$ between the control and treated samples. 


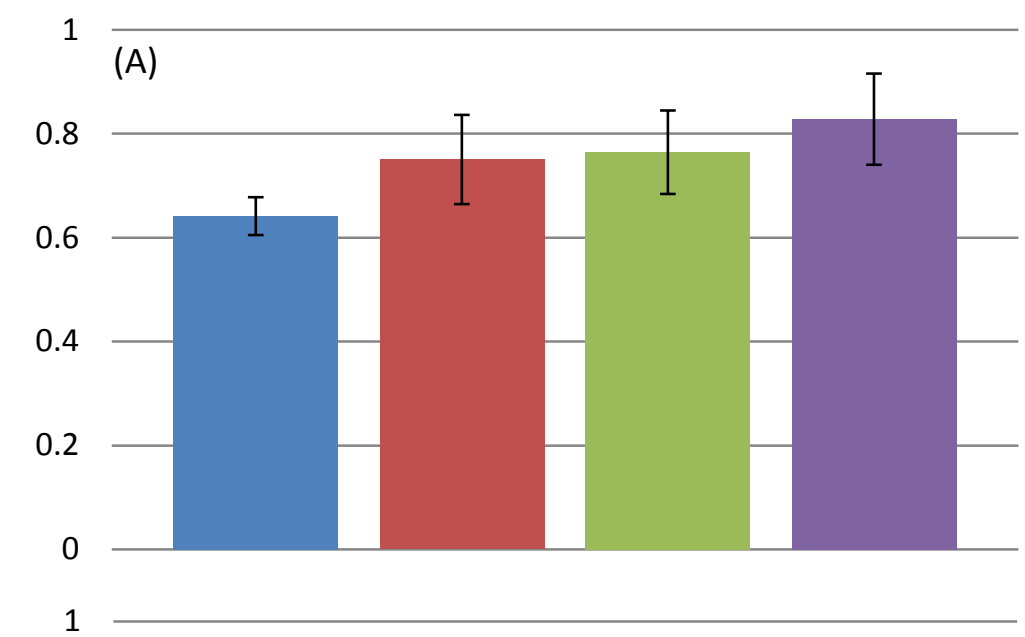

(B)
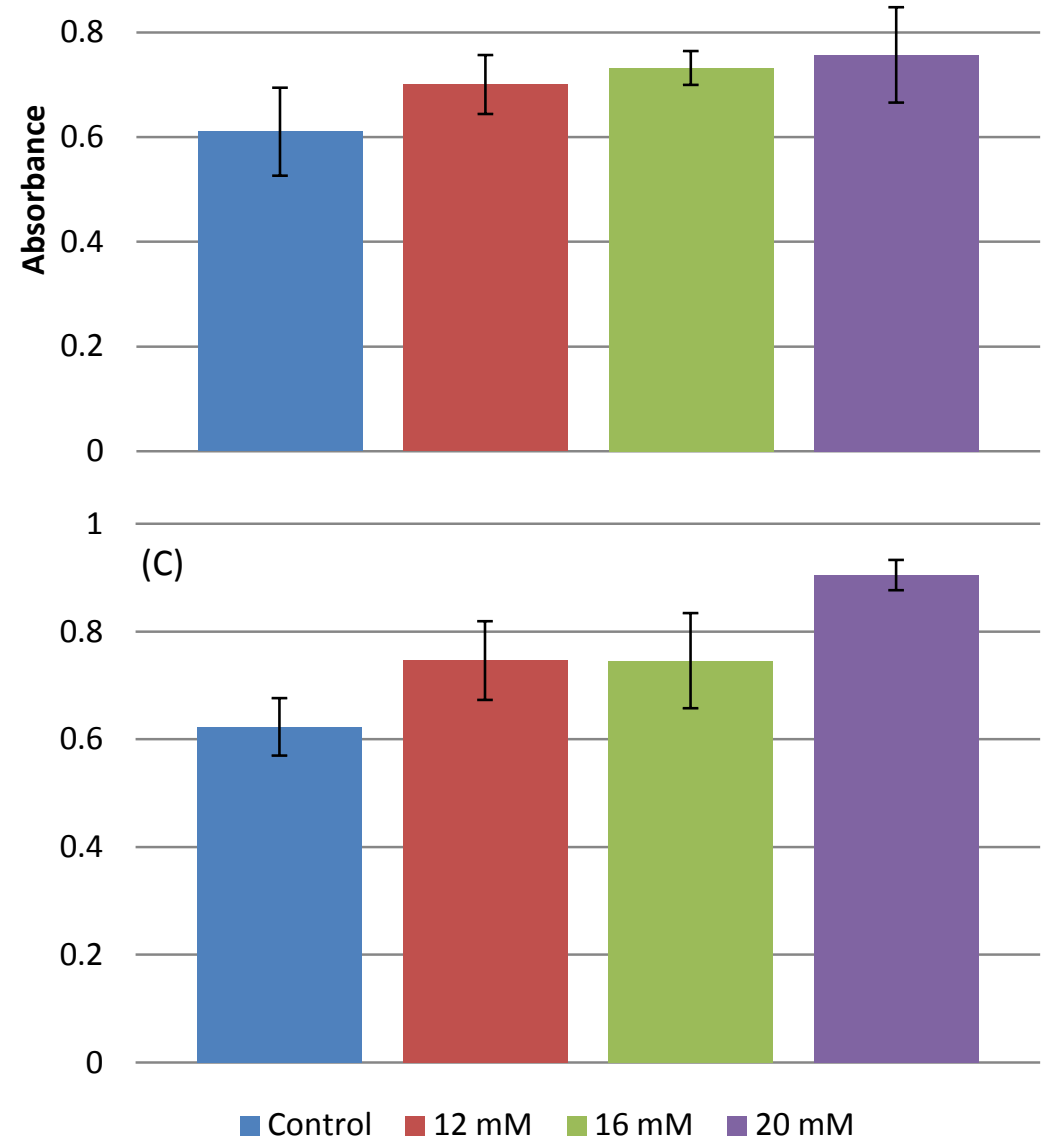

Figure 4.21 Absorbance of intracellular DNA leakage $(260 \mathrm{~nm})$ from E. coli (A), $L$. acidophilus (B), and B. animalis (C) after treatment with ZnO NPs 

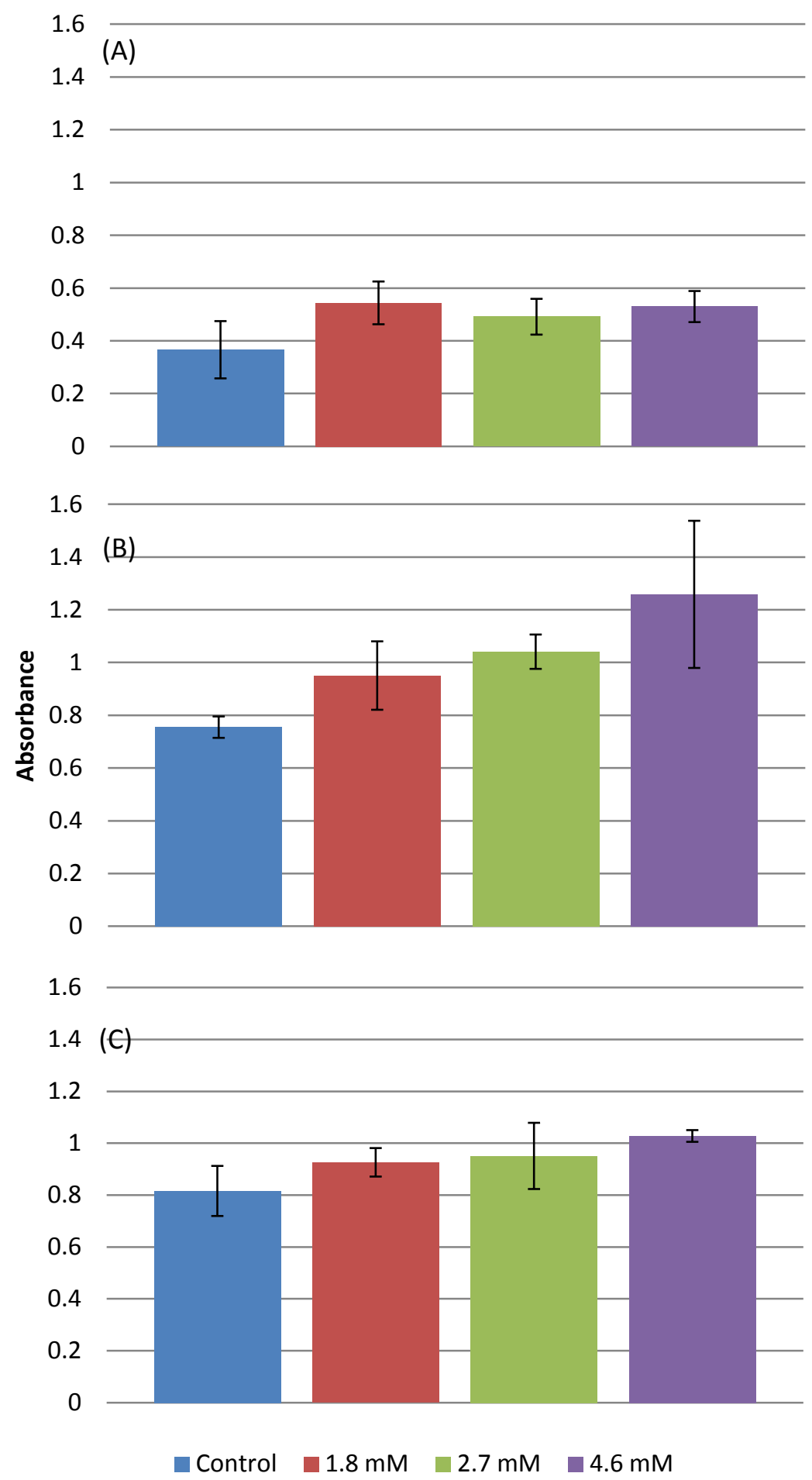

Figure 4.22 Absorbance of intracellular DNA leakage $(260 \mathrm{~nm})$ from $E$. coli (A), $L$. acidophilus (B), and B. animalis (C) after treatment with Ag NPs 


\subsection{Viability of bacterial cells}

The Bac Light ${ }^{\mathrm{TM}}$ Bacterial Viability Kit and fluorescence microscopy demonstrated to observe viability of bacterial cells after treated with $\mathrm{ZnO}$ and Ag NPs. The viability of bacterial cells of E. coli, L. acidophilus, and B. animalis incubated in respective broth medium for $10 \mathrm{~h}$, with and without the presence of $20 \mathrm{mM}$ of $\mathrm{ZnO}$ were analyzed. For treatment with Ag NPs, as shown in Tables 4.3, 4.4, and 4.5, bacterial strains exposed to Ag NPs for $6 \mathrm{~h}$, showed the most antimicrobial effect. Therefore, E. coli, L. acidophilus, and $B$. animalis incubated in their respective broth medium for $6 \mathrm{~h}$, with and without the presence of $4.6 \mathrm{mM}$ of Ag NPs were used to perform the cell viability assay using fluorescence microscopy. Figure 4.23 shows the fluorescence microscopic images of the cells untreated (Figure 4.23 A, C, E) and treated (Figure 4.23 B, D, F) with ZnO NPs. E. coli control (A) and treated (B) samples as shown in Figure 4.23, demonstrated green fluorescence in both images which indicates live cells. There were very few red fluorescent cells, indicating the presence of dead cells in the treated sample (4.23B). This result supports with previous results (Figure 4.1A) which showed no significant effects $(P \leq .05)$ of $\mathrm{ZnO}$ NPs on $E$. coli growth.

L. acidophilus and B. animalis showed similar morphological changes as those observed in SEM images (Figure 4.23D and F) after treatment of ZnO NPs. Green fluorescent cells were observed in the control image (4.23C and $\mathrm{E})$ with straight rod shape formed in a chain while, treated cells were formed in clusters or twisted around one another. However, not all twisted cells showed red fluorescence, which indicates that not all deformed cells were dead. The results support the plate count numbers in Figure 4.2B and 4.2C, that 
showed about $10^{7} \mathrm{CFU} / \mathrm{mL}$ of bacterial cells. This indicates that not all cells were affected by $\mathrm{ZnO}$ NPs and resulted in leakage of internal contents and death of cells. Fluorescence microscopic images of cells treated with Ag NPs and the controls were shown in Figure 4.24. The control samples of E. coli shown in Figure 4.24A, mostly fluoresced green, indicating live cells. Many red fluorescence cells were observed in Ag NPs treated samples (Figure 4.24B) which indicate dead cells. Not only were there red cells observed, there were also green fluorescent cells. However, as compared to $\mathrm{ZnO}$ NPs treatment which showed very few dead cells, many dead cells were observed following Ag NP treatment.

Figure 4.24 showed L. acidophilus and B. animalis untreated (Figure 4.24C, E) and treated (Figure 4.24D, F) with Ag NPs. Mostly, green fluorescent cells with straight rod shapes were observed in the untreated sample image (Figurer 4.24C, E). Both green and red fluorescent cells, in large clusters, were observed in the treated samples (Figure 4.24D, F). However, more green cells than red were observed in the treated samples, which indicated more live cells were present.

Thus, the results of viability of cells showed that not all cells were affected by $\mathrm{ZnO}$ or $\mathrm{Ag}$ NPs and resulted in cell death.

Compared to cells without NP treatment which showed well-organized single cells and non-clustered cells, cells treated with $\mathrm{ZnO}$ or Ag NPs agglomerated together and formed large clusters. Possible explanation may be electrostatic attractions between the negatively charged cell membrane of microorganisms and positively charged $\mathrm{Zn}^{+} \mathrm{or} \mathrm{Ag}^{+}$ ions from NPs. In the case of $\mathrm{Ag}$ NPs, these cannot release $\mathrm{Ag}^{+}$ions without oxygen and L. acidophilus and $B$. animalis were incubated in anaerobic condition. In spite of the 
anaerobic conditions, L. acidophilus and B. animalis similarly showed agglomerations. This may be due to the exposure of $\mathrm{Ag}$ NPs to oxygen and release of $\mathrm{Ag}^{+}$ions, during the preparations of bacterial viability assay and fluorescence microscopy, that subsequently reacted with the negatively charged bacterial surfaces. 


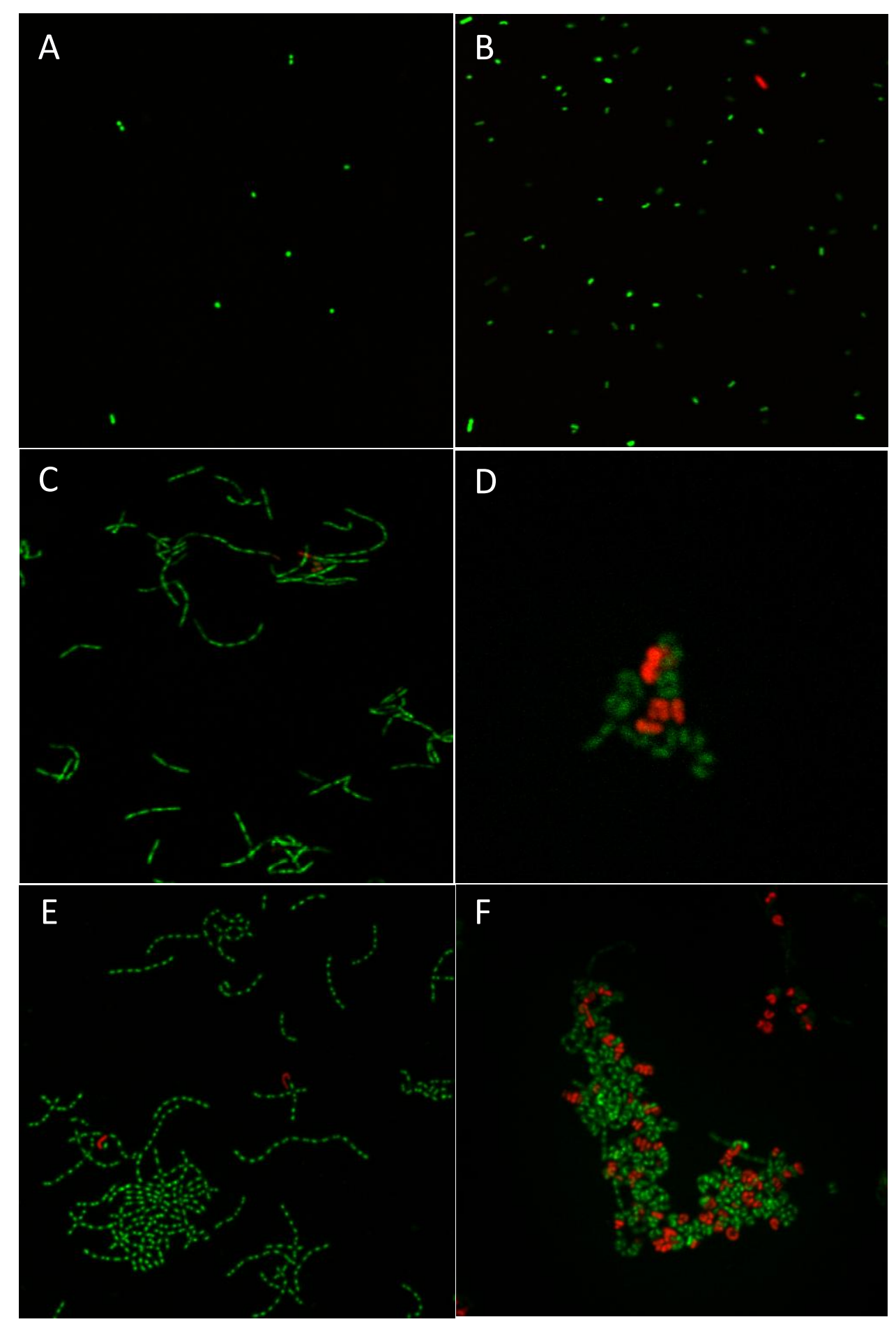

Figure 4.23 $\mathrm{BacLight}^{\mathrm{TM}}$ fluorescence microscopic images of cells untreated and treated with $20 \mathrm{mM}$ ZnO NPs (A) E. coli untreated, (B) E. coli treated, (C) L. acidophilus untreated, (D) L. acidophilus treated, (E) B. animalis untreated, (F) B. animalis treated. 


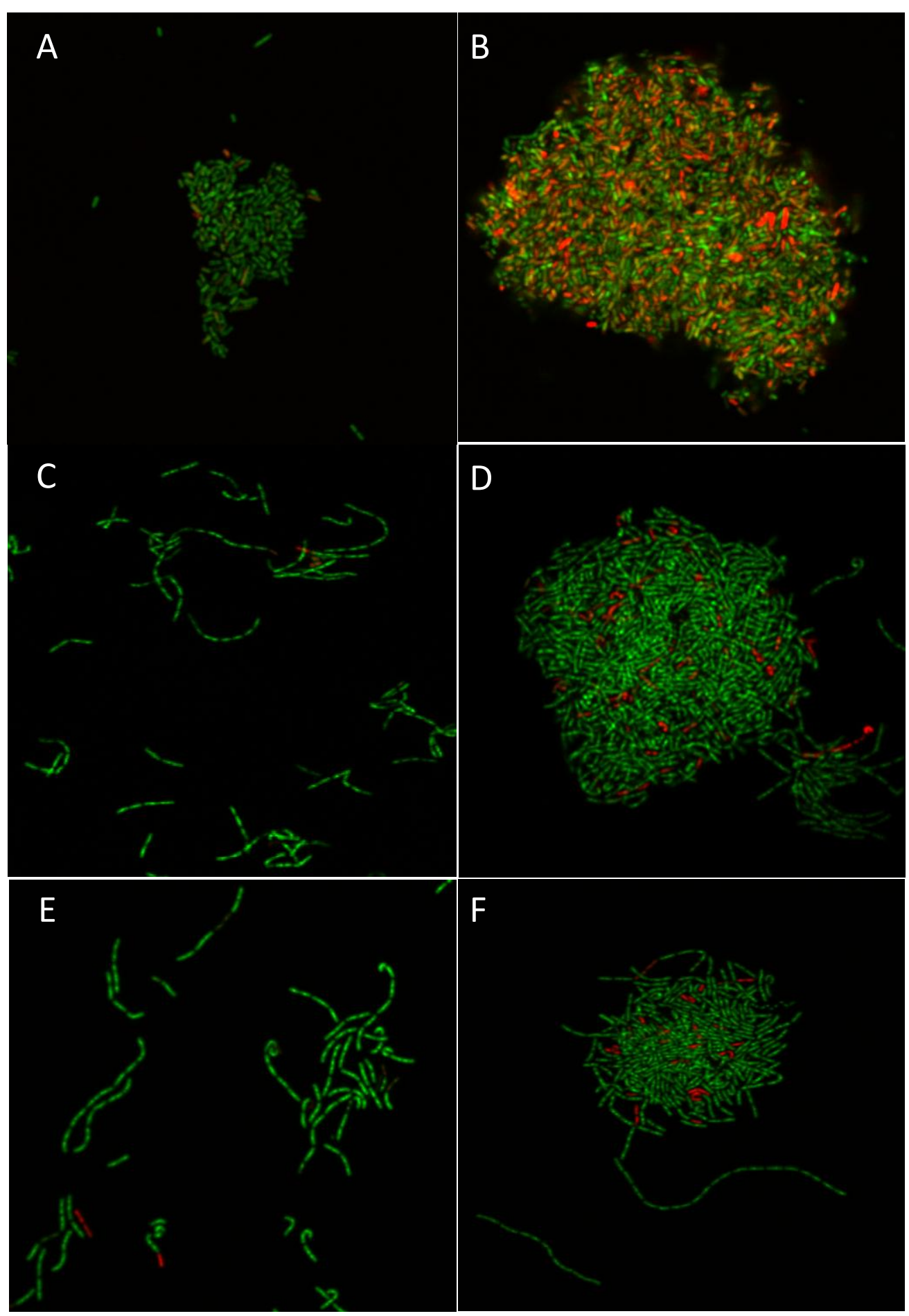

Figure 4.24 $\mathrm{BacLight}^{\mathrm{TM}}$ fluorescence microscopic images of cells untreated and treated with $4.6 \mathrm{mM}$ Ag NPs (A) E. coli untreated, (B) E. coli treated, (C) L. acidophilus untreated, (D) L. acidophilus treated, (E) B. animalis untreated, (F) B. animalis treated. 


\section{CONCLUSIONS}

In summary, $\mathrm{ZnO}$ and $\mathrm{Ag}$ NPs exhibited mild antibacterial effects against intestinal bacteria, E. coli K-12, L. acidophilus $\mathrm{ADH}$, and B. animalis Bif-6. Inhibitory effects slightly increased as the concentrations of NPs increased.

Results showed that bacterial strains exposed to ZnO NPs for $10 \mathrm{~h}$ and Ag NPs for $6 \mathrm{~h}$ suffered the most antimicrobial effect. However, the number of treated cells were within $1 \log \mathrm{CFU} / \mathrm{mL}$ less than that of the control and the reduction percentage in the number of cells were about $10 \%$ or less. Therefore, SEM and TEM were performed after strains were exposed to $\mathrm{ZnO}$ NPs for $10 \mathrm{~h}$ and Ag NPs for $6 \mathrm{~h}$. The results of SEM and TEM images and EDS demonstrated the morphological changes of the cells and the adherence of NPs to bacterial cells. Some externally and internally damaged cells were observed. However, not all cells were damaged, and there were still many cells in normal size with intact intracellular structures and well-organized intracellular contents which correlated with the results of numbers of cells reduction. Also, results of the UV absorbance and cell viability assay correlated with the previous experiment results. The results of the UV absorbance indicated that no significant amounts of internal cellular contents were leaked due to NPs. Finally, the viability assay of bacterial cells confirmed that more live than dead cells were present after treatment with NPs. Overall results indicate that not all cells were affected by NPs.

According to all results obtained in this study, $\mathrm{ZnO}$ and Ag NPs have very mild inhibitory effects on intestinal bacteria as compared to those of pathogenic 
microorganisms that have been done in previous studies (Sondi and Salopek-Sondi 2004; Brayer and others 2006; Kim and others 2007; Jones and others 2008; Martinez-Castanon 2008; Raffi and others 2009; Liu and others 2009; Jin and others 2009; Tayel 2010; Xie and others 2011; Mirhosseini and Firouzabadi 2013). The contamination level of ZnO and Ag NPs in food sample, if present, is very low, and in this study, a much higher concentration of NPs were tested. The data obtained from this study indicate that the food contaminated with $\mathrm{ZnO}$ and $\mathrm{Ag}$ NPs offers a negligible threat to the beneficial gut microflora. 


\section{REFERENCES}

Amro NA, Kotra LP, Wadu-Mesthrige K, Bulychev A, Mobashery S, Liu GY. 2000. High-resolution atomic force microscopy studies of the Escherichia coli outer membrane: structural basis for permeability. Langmuir 16(6):2789-96.

Andersen ES, Dong M, Nielsen MM, Jahn K, Subramani R, Mamdouh W, Golas MM, Sander B, Stark H, Oliveira CL. 2009. Self-assembly of a nanoscale DNA box with a controllable lid. Nature 459(7243):73-6.

Arora S, Jain J, Rajwade J, Paknikar K. 2008. Cellular responses induced by silver nanoparticles: In vitro studies. Toxicology Letters 179(2):93-100.

Arora S, Jain J, Rajwade J, Paknikar K. 2009. Interactions of silver nanoparticles with primary mouse fibroblasts and liver cells. Toxicology and Applied Pharmacology 236(3):310-8.

Ashkarran AA, Ghavami M, Aghaverdi H, Stroeve P, Mahmoudi M. 2012. Bacterial Effects and Protein Corona Evaluations: Crucial Ignored Factors in the Prediction of BioEfficacy of Various Forms of Silver Nanoparticles. Chemical Research in Toxicology 25(6):1231-42.

Baek YW, An YJ. 2011. Microbial toxicity of metal oxide nanoparticles (CuO, NiO, $\mathrm{ZnO}$, and $\mathrm{Sb}_{2} \mathrm{O}_{3}$ to Escherichia coli, Bacillus subtilis, and Streptococcus aureus. Science of the Total Environment 409(8):1603-8.

Baker C, Pradhan A, Pakstis L, Pochan DJ, Shah SI. 2005. Synthesis and antibacterial properties of silver nanoparticles. Journal of Nanoscience and Nanotechnology 5(2):2449.

Bennett D, Schuurbiers D. 2005. Nanobiotechnology: responsible action on issues in society and ethics. NSTI Nanotech. Vol. 2:765-8.

Bolla JM, Alibert-Franco S, Handzlik J, Chevalier J, Mahamoud A, Boyer G, KiećKononowicz K, Pagès JM. 2011. Strategies for bypassing the membrane barrier in multidrug resistant Gram-negative bacteria. FEBS Letters 585(11):1682-90.

Borriello S. 1986. Microbial flora of the gastrointestinal tract. Microbial metabolism in the digestive tract. CRC Press, Inc., Boca Raton, Fla:2-16.

Brayner R, Ferrari-Iliou R, Brivois N, Djediat S, Benedetti MF, Fiévet F. 2006. Toxicological impact studies based on Escherichia coli bacteria in ultrafine $\mathrm{ZnO}$ nanoparticles colloidal medium. Nano Letters 6(4):866-70. 
Brown M, Allison D, Gilbert P. 1988. Resistance of bacterial biofilms to antibiotics a growth-rate related effect? Journal of Antimicrobial Chemotherapy 22(6):777-80.

Brunner TJ, Wick P, Manser P, Spohn P, Grass RN, Limbach LK, Bruinink A, Stark WJ. 2006. In vitro cytotoxicity of oxide nanoparticles: comparison to asbestos, silica, and the effect of particle solubility. Environmental Science \& Technology 40(14):4374-81.

Chen M, von Mikecz A. 2005. Formation of nucleoplasmic protein aggregates impairs nuclear function in response to $\mathrm{SiO}_{2}$ nanoparticles. Experimental Cell Research 305(1):51-62.

Choi O, Deng KK, Kim N-J, Ross Jr L, Surampalli RY, Hu Z. 2008. The inhibitory effects of silver nanoparticles, silver ions, and silver chloride colloids on microbial growth. Water Research 42(12):3066-74.

Choi O, Hu Z. 2008. Size dependent and reactive oxygen species related nanosilver toxicity to nitrifying bacteria. Environmental Science \& Technology 42(12):4583-8.

Christen V, Fent K. 2012. Verena Christen, Karl Fent. Chemosphere 87(4):423-34.

Das GK, Chan PP, Teo A, Loo JSC, Anderson JM, Tan TTY. 2010. In vitro cytotoxicity evaluation of biomedical nanoparticles and their extracts. Journal of Biomedical Materials Research Part A 93(1):337-46.

Dibrov P, Dzioba J, Gosink KK, Häse CC. 2002. Chemiosmotic mechanism of antimicrobial activity of Ag+ in Vibrio cholerae. Antimicrobial Agents and Chemotherapy 46(8):2668-70.

Dragieva I, Stoeva S, Stoimenov P, Pavlikianov E, Klabunde K. 1999. Complex formation in solutions for chemical synthesis of nanoscaled particles prepared by borohydride reduction process. Nanostructured materials 12(1):267-70.

Duncan TV. 2011. Applications of nanotechnology in food packaging and food safety: Barrier materials, antimicrobials and sensors. Journal of Colloid and Interface Science 363(1):1-24.

Elsaesser A, Howard CV. 2012. Toxicology of nanoparticles. Advanced Drug Delivery Reviews 64(2):129-37.

Fabrega J, Fawcett SR, Renshaw JC, Lead JR. 2009. Silver nanoparticle impact on bacterial growth: effect of $\mathrm{pH}$, concentration, and organic matter. Environmental Science \&Technology 43(19):7285-90. 
Frankel WL, Zhang W, Singh A, Klurfeld DM, Don S, Sakata T, Modlin I, Rombeau J. 1994. Mediation of the trophic effects of short-chain fatty acids on the rat jejunum and colon. Gstroenterology-Baltimore then Philadelphia- 106:375-80.

Fu G, Vary PS, Lin C-T. 2005. Anatase TiO2 nanocomposites for antimicrobial coatings. The Journal of Physical Chemistry B 109(18):8889-98.

Gleiter H. 2000. Nanostructured materials: basic concepts and microstructure. Acta materialia 48(1):1-29.

Guarner F, Malagelada J-R. 2003. Gut flora in health and disease. The Lancet 361(9356):512-9.

Guzman M, Dille J, Godet S. 2012. Synthesis and antibacterial activity of silver nanoparticles against gram-positive and gram-negative bacteria. Nanomedicine: Nanotechnology, Biology and Medicine 8(1):37-45.

Hajipour MJ, Fromm KM, AkbarAshkarran A, Jimenez de Aberasturi D, Larramendi IRd, Rojo T, Serpooshan V, Parak WJ, Mahmoudi M. 2012. Antibacterial properties of nanoparticles. Trends in Biotechnology 30(10):499-511

Hamouda T, Myc A, Donovan B, Shih AY, Reuter JD, Baker JR. 2001. A novel surfactant nanoemulsion with a unique non-irritant topical antimicrobial activity against bacteria, enveloped viruses and fungi. Microbiological Research 156(1):1-7.

Hassan AA, Sandre O, Cabuil V, Tabeling P. 2008. Synthesis of iron oxide nanoparticles in a microfluidic device: preliminary results in a coaxial flow millichannel. Chemical Communications (15):1783-5.

Howard KA, Kjems J. 2007. Polycation-based nanoparticle delivery for improved RNA interference therapeutics 7(12):1811-1822.

Huh AJ, Kwon YJ. 2011. "Nanoantibiotics": A new paradigm for treating infectious diseases using nanomaterials in the antibiotics resistant era. Journal of Controlled Release 156(2):128-45.

Jeng HA, Swanson J. 2006. Toxicity of metal oxide nanoparticles in mammalian cells. Journal of Environmental Science and Health Part A 41(12):2699-711.

Ji JH, Jung JH, Kim SS, Yoon J-U, Park JD, Choi BS, Chung YH, Kwon IH, Jeong J, Han BS. 2007. Twenty-eight-day inhalation toxicity study of silver nanoparticles in Sprague-Dawley rats. Inhalation toxicology 19(10):857-71. 
Ji JH, Jung JH, Kim SS, Yoon J-U, Park JD, Choi BS, Chung YH, Kwon IH, Jeong J, Han BS. 2007. Twenty-eight-day inhalation toxicity study of silver nanoparticles in Sprague-Dawley rats. Inhalation toxicology 19(10):857-71.

Jiang P, Zhou JJ, Fang HF, Wang CY, Wang ZL, Xie SS. 2007. Hierarchical shelled ZnO structures made of bunched nanowire arrays. Advanced Functional Materials 17(8):130310.

Jin T, Sun D, Su J, Zhang H, Sue HJ. 2009. Antimicrobial efficacy of zinc oxide quantum dots against Listeria monocytogenes, Salmonella Enteritidis, and Escherichia coli O157: H7. Journal of Food Science 74(1):M46-M52.

Jin Y, Kannan S, Wu M, Zhao JX. 2007. Toxicity of luminescent silica nanoparticles to living cells. Chemical Research in Toxicology 20(8):1126-33.

Jones N, Ray B, Ranjit KT, Manna AC. 2008. Antibacterial activity of ZnO nanoparticle suspensions on a broad spectrum of microorganisms. FEMS Microbiology Letters 279(1):71-6.

Kim JS, Kuk E, Yu KN, Kim JH, Park SJ, Lee HJ, Kim SH, Park YK, Park YH, Hwang CY. 2007. Antimicrobial effects of silver nanoparticles. Nanomedicine: Nanotechnology, Biology and Medicine 3(1):95-101.

Kiss B, Biro T, Czifra G, Tóth BI, Kertesz Z, Szikszai Z, Kiss ÁZ, Juhasz I, Zouboulis CC, Hunyadi J. 2008. Investigation of micronized titanium dioxide penetration in human skin xenografts and its effect on cellular functions of human skin-derived cells. Experimental Dermatology 17(8):659-67.

Kumar CS. 2006. Nanomaterials: toxicity, health and environmental issues: Wiley-VCH Weinheim.

Lademann J, Weigmann H-J, Rickmeyer C, Barthelmes H, Schaefer H, Mueller G, Sterry W. 1999. Penetration of titanium dioxide microparticles in a sunscreen formulation into the horny layer and the follicular orifice. Skin Pharmacology and Physiology 12(5):24756.

Lai JC, Lai MB, Jandhyam S, Dukhande VV, Bhushan A, Daniels CK, Leung SW. 2008. Exposure to titanium dioxide and other metallic oxide nanoparticles induces cytotoxicity on human neural cells and fibroblasts. International Journal of Nanomedicine 3(4):533.

Lam P, Chan E, Ho W, Liew C. 2004. In vitro cytotoxicity testing of a nanocrystalline silver dressing (Acticoat) on cultured keratinocytes. British Journal of Biomedical Science 61(3):125-7. 
Lara HH, Garza-Treviño EN, Ixtepan-Turrent L, Singh DK. 2011. Silver nanoparticles are broad-spectrum bactericidal and virucidal compounds. J Nanobiotechnology 9:30.

Lee H, Yeo S, Jeong S. 2003. Antibacterial effect of nanosized silver colloidal solution on textile fabrics. Journal of Materials Science 38(10):2199-204.

Levison ME. 1990. Intra-abdominal infections. In: Stein JH ed. Internal Medicine. 27481.

Li X, Wang L, Fan Y, Feng Q, Cui FZ. 2012. Biocompatibility and toxicity of nanoparticles and nanotubes. Journal of Nanomaterials 2012:1-19.

Lin P, Chen J-W, Chang LW, Wu JP, Redding L, Chang H, Yeh T-K, Yang CS, Tsai MH, Wang H-J. 2008. Computational and ultrastructural toxicology of a nanoparticle, Quantum Dot 705, in mice. Environmental Science \& Technology 42(16):6264-70.

Liu HL, Dai SA, Fu KY, Hsu SH. 2010. Antibacterial properties of silver nanoparticles in three different sizes and their nanocomposites with a new waterborne polyurethane. International Journal of Nanomedicine 5:1017-28.

Liu Y, He L, Mustapha A, Li H, Hu Z, Lin M. 2009. Antibacterial activities of zinc oxide nanoparticles against Escherichia coli O157: H7. Journal of Applied Microbiology 107(4):1193-201.

Lu C, Brauer MJ, Botstein D. 2009. Slow growth induces heat-shock resistance in normal and respiratory-deficient yeast. Molecular Biology of the Cell 20(3):891-903.

Mah TFC, O'Toole GA. 2001. Mechanisms of biofilm resistance to antimicrobial agents. Trends in Microbiology 9(1):34-9.

Maillard JY, Hartemann P. 2012. Silver as an antimicrobial: facts and gaps in knowledge. Critical Reviews in Microbiology 39(4):373-83.

Maness PC, Smolinski S, Blake DM, Huang Z, Wolfrum EJ, Jacoby WA. 1999. Bactericidal activity of photocatalytic $\mathrm{TiO} 2$ reaction: toward an understanding of its killing mechanism. Applied and Environmental Microbiology 65(9):4094-8.

Martinez-Castanon G, Nino-Martinez N, Martinez-Gutierrez F, Martinez-Mendoza J, Ruiz F. 2008. Synthesis and antibacterial activity of silver nanoparticles with different sizes. Journal of Nanoparticle Research 10(8):1343-8.

McDonnell G, Russell AD. 1999. Antiseptics and disinfectants: activity, action, and resistance. Clinical Microbiology Reviews 12(1):147-79. 
Meyer M, Kuusi O. 2006. Nanotechnology: Generalization in an inter-disciplinary field of science and technology. Nanotechnology Challenges: Implications for Philosophy, Ethics and Society 10:153-168.

Mirhosseini M, Firouzabadi FB. 2012. Antibacterial activity of zinc oxide nanoparticle suspensions on food-borne pathogens. International Journal of Dairy Technology.

Miyazawa E, Iwabuchi A, Yoshida T. 1996. Phytate breakdown and apparent absorption of phosphorus, calcium and magnesium in germfree and conventionalized rats. Nutrition Research 16(4):603-13.

Moraru CI, Panchapakesan CP, Huang Q, Takhistov P, Sean L, Kokini JL. 2003. Nanotechnology: a new frontier in food science. Food Technology 57(12):24-9.

Morones JR, Elechiguerra JL, Camacho A, Holt K, Kouri JB, Ramírez JT, Yacaman MJ. 2005. The bactericidal effect of silver nanoparticles. Nanotechnology 16(10):2346-53.

Murphy CJ, Gole AM, Stone JW, Sisco PN, Alkilany AM, Goldsmith EC, Baxter SC. 2008. Gold nanoparticles in biology: beyond toxicity to cellular imaging. Accounts of Chemical Research 41(12):1721-30.

Musee N, Thwala M, Nota N. 2011. The antibacterial effects of engineered nanomaterials: implications for wastewater treatment plants. Journal of Environmental Monitoring 13(5):1164-83.

Oberdörster G, Sharp Z, Atudorei V, Elder A, Gelein R, Kreyling W, Cox C. 2004. Translocation of inhaled ultrafine particles to the brain. Inhalation Toxicology 16(67):437-45.

Paddle-Ledinek JE, Nasa Z, Cleland HJ. 2006. Effect of different wound dressings on cell viability and proliferation. Plastic and Reconstructive Surgery 117(7S):110S-8S.

Pal S, Tak YK, Song JM. 2007. Does the antibacterial activity of silver nanoparticles depend on the shape of the nanoparticle? A study of the gram-negative bacterium Escherichia coli. Applied and Environmental Microbiology 73(6):1712-20.

Pan Y, Neuss S, Leifert A, Fischler M, Wen F, Simon U, Schmid G, Brandau W, Jahnen-Dechent W. 2007. Size-Dependent Cytotoxicity of Gold Nanoparticles. Small 3(11):1941-9.

Pan Z, Lee W, Slutsky L, Clark RA, Pernodet N, Rafailovich MH. 2009. Adverse effects of titanium dioxide nanoparticles on human dermal fibroblasts and how to protect cells. Small 5(4):511-20. 
Poon VK, Burd A. 2004. In vitro cytotoxity of silver: implication for clinical wound care. Burns 30(2):140-7.

Pramanik A, Laha D, Bhattacharya D, Pramanik P, Karmakar P. 2012. A novel study of antibacterial activity of copper iodide nanoparticle mediated by DNA and membrane damage. Colloids and Surfaces B: Biointerfaces 96:50-5

Raffi M, Hussain F, Bhatti T, Akhter J, Hameed A, Hasan M. 2008. Antibacterial characterization of silver nanoparticles against E. coli ATCC-15224. Journal of Materials Science and Technology 24(2):192-6.

Ratte HT. 1999. Bioaccumulation and toxicity of silver compounds: A review. Environmental Toxicology and Chemistry 18(1):89-108.

Ratyakshi, Chauhan R. 2009. Colloidal synthesis of silver nano particles. Asian Journal of Chemistry 21(10):113-6.

Reddy KM, Feris K, Bell J, Wingett DG, Hanley C, Punnoose A. 2007. Selective toxicity of zinc oxide nanoparticles to prokaryotic and eukaryotic systems. Applied Physics Letters 90(21):213902--3.

Roberfroid M, Bornet F, Bouley C, Cummings J. 1995. Colonic Microflora: Nutrition and Health0. Summary and Conclusions of an International Life Sciences Institute (ILSI)[Europe] Workshop held in Barcelona, Spain. Nutrition Reviews 53(5):127-30.

Salminen S, Bouley C, Boutron-Ruault M, Cummings J, Franck A, Gibson G, Isolauri E, Moreau M, Roberfroid M, Rowland I. 1998. Functional food science and gastrointestinal physiology and function. British Journal of Nutrition 80(1):S147.

Sambhy V, MacBride MM, Peterson BR, Sen A. 2006. Silver bromide nanoparticle/polymer composites: dual action tunable antimicrobial materials. Journal of the American Chemical Society 128(30):9798-808.

Sawai J. 2003. Quantitative evaluation of antibacterial activities of metallic oxide powders $(\mathrm{ZnO}, \mathrm{MgO}$ and $\mathrm{CaO})$ by conductimetric assay. Journal of Microbiological Methods 54(2):177-82.

Seil JT, Webster TJ. 2012. Antimicrobial applications of nanotechnology: methods and literature. International Journal of Nanomedicine 7:2767.

Sigel RW. 1993. Master of Science Engineering B:19-37. 
Simon GL, Gorbach SL. 1986. The human intestinal microflora. Digestive Diseases and Sciences 31(9):147-62.

Singleton P. 2004. Bacteria in biology, biotechnology and medicine: John Wiley \& Sons Ltd., Chichester, UK.

Sondi I, Salopek-Sondi B. 2004. Silver nanoparticles as antimicrobial agent: a case study on E. coli as a model for Gram-negative bacteria. Journal of Colloid and Interface Science 275(1):177-82.

Soto K, Garza K, Murr L. 2007. Cytotoxic effects of aggregated nanomaterials. Acta Biomaterialia 3(3):351-8.

Stewart PS. 2002. Mechanisms of antibiotic resistance in bacterial biofilms. International Journal of Medical Microbiology 292(2):107-13.

Stoimenov PK, Klinger RL, Marchin GL, Klabunde KJ. 2002. Metal oxide nanoparticles as bactericidal agents. Langmuir 18(17):6679-86.

Sung JH, Ji JH, Park JD, Yoon JU, Kim DS, Jeon KS, Song MY, Jeong J, Han BS, Han JH. 2009. Subchronic inhalation toxicity of silver nanoparticles. Toxicological Sciences 108(2):452-61.

Suryanarayana C. 1995. Nanocrystalline materials. International Materials Reviews 40(2):41-64.

Tayel AA, El-Tras WF, Moussa S, El-Baz AF, Mahrous H, Salem MF, Brimer L. 2011. Antibacterial action of zinc oxide nanoparticles against foodborne pathogens. Journal of Food Safety 31(2):211-8.

Thill A, Zeyons O, Spalla O, Chauvat F, Rose J, Auffan M, Flank AM. 2006.

Cytotoxicity of $\mathrm{CeO} 2$ nanoparticles for Escherichia coli. Physico-chemical insight of the cytotoxicity mechanism. Environmental Science \& Technology 40(19):6151-6.

VithaláGhule A. 2006. Preparation and characterization of $\mathrm{ZnO}$ nanoparticles coated paper and its antibacterial activity study. Green Chemistry 8(12):1034-41.

Wan Y, Zhang D, Wang Y, Qi P, Wu J, Hou B. 2011. Vancomycin-functionalised Ag@ $\mathrm{TiO}_{2}$ phototoxicity for bacteria. Journal of Hazardous Materials 186(1):306-12.

Wang F, Gao F, Lan M, Yuan H, Huang Y, Liu J. 2009. Oxidative stress contributes to silica nanoparticle-induced cytotoxicity in human embryonic kidney cells. Toxicology in vitro 23(5):808-15. 
Wang S, Lawson R, Ray PC, Yu H. 2011. Toxic effects of gold nanoparticles on Salmonella Typhimurium bacteria. Toxicology and Industrial Health 27(6):547-54.

Weiss J, Takhistov P, McClements DJ. 2006. Functional materials in food nanotechnology. Journal of Food Science 71(9):R107-R16.

Woodhouse E. 2004. Nanotechnology Controversies-Guest Editorial. Technology and Society Magazine, IEEE 23(4):6-8.

Wu B, Huang R, Sahu M, Feng X, Biswas P, Tang YJ. 2010. Bacterial responses to Cudoped $\mathrm{TiO}_{2}$ nanoparticles. Science of the Total Environment 408(7):1755-1758.

Xie Y, He Y, Irwin PL, Jin T, Shi X. 2011. Antibacterial activity and mechanism of action of zinc oxide nanoparticles against Campylobacter jejuni. Applied and Environmental Microbiology 77(7):2325-31.

Yang H, Liu C, Yang D, Zhang H, Xi Z. 2009. Comparative study of cytotoxicity, oxidative stress and genotoxicity induced by four typical nanomaterials: the role of particle size, shape and composition. Journal of Applied Toxicology 29(1):69-78.

Younes H, Coudray C, Bellanger J, Demigné C, Rayssiguier Y, Rémésy C. 2001. Effects of two fermentable carbohydrates (inulin and resistant starch) and their combination on calcium and magnesium balance in rats. British Journal of Nutrition 86(04):479-85.

Zhang L, Jiang Y, Ding Y, Povey M, York D. 2007. Investigation into the antibacterial behaviour of suspensions of $\mathrm{ZnO}$ nanoparticles ( $\mathrm{ZnO}$ nanofluids). Journal of Nanoparticle Research 9(3):479-89.

Zhou J, Xu NS, Wang ZL. 2006. Dissolving behavior and stability of ZnO wires in biofluids: a study on biodegradability and biocompatibility of $\mathrm{ZnO}$ nanostructures. Advanced Materials 18(18):2432-5. 